\title{
Memorias feministas de la lucha por el aborto en San Juan, Argentina
}

\author{
Feminist Memories of the Fight for Abortion \\ in San Juan, Argentina
}

Fecha de recepción: 16/09/2021

Fecha de aceptación: 15/12/2021

Fecha de publicación: 07/03/2022

https://doi.org/10.48102/if.2022.v2.n1.211

Dolores Córdoba*

dolocordoba656@gmail.com

ORCID: https://orcid.org/0000-0003-1236-0073

Licenciada en Ciencias Políticas

Universidad Nacional de San Juan

Argentina

Gabriela Lucero**

gabylucdesanjuan@gmail.com

ORCID: https://orcid.org/0000-0001-6556-5537

Licenciada en Comunicación Social

Universidad Nacional de San Juan

Argentina

\begin{abstract}
* Dolores Córdoba es licenciada en Ciencias Políticas por la Universidad Nacional de San Juan (UNSJ). Diploma Superior en Diversidad Sexual y Derechos Humanos, otorgado por el Consejo Latinoamericano de Ciencias Sociales (CLACSO) y la Federación Argentina de Lesbianas, Gays, Bisexuales y Trans (FALGBT). Especialista en Epistemologías del Sur (CLACSO). Docente, investigadora y extensionista en la UNSJ. Activista en Ni Unx Menos San Juan. Miembro de TRAMA, red de mujeres que trabajan con mujeres campesinas e indígenas. Colaboradora en Radio Comunitaria La Lechuza. Integra el Equipo de Investigación en Género y Ciudadanía del Instituto de Investigaciones Socio Económicas (IISE) de la Facultad de Ciencias Sociales (FACSO) en la UNSJ. Sus líneas de investigación son: violencia de género, feminismos, ciudadanía y géneros, violencia sexual, maternidades y crianzas.

** Gabriela Lucero es licenciada en Comunicación Social. Especialista en Métodos y Técnicas de Investigación Social (CLACSO). Diplomada en Prácticas Sociales Educativas. Episte-
\end{abstract}




\author{
Yanina Iturrieta*** \\ yani.iturrieta@gmail.com \\ ORCID: https://orcid.org/0000-0002-1625-5425 \\ Licenciada en Sociología \\ Universidad Nacional de San Juan \\ Argentina \\ Paloma Chousal Lizama**** \\ palomachousal@gmail.com \\ ORCID: https://orcid.org/0000-0002-9305-8206 \\ Licenciada en Sociología \\ Universidad Nacional de San Juan \\ Argentina
}

mología, metodologías y praxis de la enseñanza-aprendizaje en comunidad por la Universidad Nacional de Cuyo (UNCUYO). Docente, investigadora y extensionista en la Universidad Nacional de San Juan (UNSJ). Activista en Ni Unx Menos San Juan y en la Red de Comunicadorxs con Perspectiva de Género de San Juan. Sus líneas de investigación y extensión son: comunicación y derechos humanos, feminismos, género, economía social y solidaria.

*** Yanina Iturrieta es licenciada en Sociología por la Universidad Nacional de San Juan (UNSJ). Profesora en Sociología por la UNSJ. En 2019 obtuvo una beca doctoral del Consejo Nacional de Investigaciones Científicas y Técnicas (CONICET). Milita en la organización feminista Las Hilarias Socorristas en Red desde su conformación en 2014. Es docente de las asignaturas de Teoría Sociológica y Antropología Social de la carrera de Sociología en la Facultad de Ciencias Sociales (FACSO). Es miembro del Espacio de Sociología Feminista(s) y del Programa de Estudios del Trabajo, el Ambiente y la Sociedad (PETAS) de la UNSJ. Codirige el proyecto interno "Participación de mujeres y diversidades sexo-genéricas en los procesos sociales y políticos de San Juan. Periodo 2010-2021" (FACSO-UNSJ). Ha participado en proyectos de investigación y desarrollo vinculados a temáticas de género, trabajo, poder, conflictividad y criminalización. Actualmente sus líneas de investigación son: políticas feministas, políticas del cuerpo y la sexualidad; sociología de los afectos y emociones; política, experiencias y luchas por el aborto.

$\star * * *$ Paloma Chousal Lizama es licenciada y profesora en Sociología por la Universidad Nacional de San Juan (UNSJ). En 2019 obtuvo una beca doctoral del CONICET. Cursa el doctorado en Ciencias Sociales de la UNSJ. Se está especializando en Estudios de Género y Análisis Feministas. Sus líneas de investigación refieren a: políticas feministas, sociología de los afectos y emociones, construcción de archivos afectivos y visuales por el aborto, significaciones y discursos sociales por el aborto en San Juan. Es parte del Espacio de Sociología Feminista(s) de la Facultad de Ciencias Sociales (FACSO). Actualmente es cocoordinadora del Gabinete de Estudios e Investigación en Sociología de la FACSO. Es docente adjunta en las cátedras Introducción al Conocimiento Científico y Epistemología de las Ciencias Sociales de la carrera de Sociología. Es representante de la UNSJ en el Consejo Provincial de Protección Integral de la Mujer y la Comunidad LGBTIQ+. 


\section{Resumen}

Destacamos que en Argentina existe una larga tradición de lucha por parte de los movimientos feministas: desde principios del siglo XIX hasta la actualidad, distintas mujeres han dejado huella en nuestra historia. Conscientes de este pasado, el objetivo de este trabajo es rememorar y analizar las luchas feministas por el derecho al aborto en la provincia cordillerana de San Juan. A partir de la identificación del fenómeno de la "marea verde" como un movimiento inspirador que supo renovar el entusiasmo de gran parte del movimiento feminista nacional y latinoamericano, nos proponemos reescribir nuestra memoria feminista local desde un diálogo situado y colectivo. Asimismo, intentamos poner de relieve los sucesos, debates, tensiones y manifestaciones que de manera singular nos permitieron tejer nuevas formas de pensar y hacer política y redefinir las militancias feministas locales.

Este trabajo es una primera aproximación, desde los estudios de la memoria y los archivos feministas, a las luchas feministas por el aborto en San Juan. A partir de él, esperamos poder reconstruir las especificidades, aún no retratadas, que la marea verde imprimió en San Juan.

\section{Palabras clave}

Aborto, marea verde, feminismos situados, memoria, archivos feministas.

\section{Abstract}

We point out that in Argentina there is a long tradition of struggle by feminist movements: from the early nineteenth century to the present, different women have left their mark on our history. Aware of this past, the aim of this paper is to recall and analyze the feminist struggles for the right to abortion in the mountainous province of San Juan. From the identification of the "marea verde" ("green tide") phenomenon as an inspiring movement that was able to renew the enthusiasm of much of the national and Latin American feminist movement, we propose to rewrite our local feminist memory from a situated and collective dialogue. Likewise, we try to highlight the events, debates, tensions, and manifestations that in a singular way allowed us to weave new ways of thinking and doing politics and redefine local feminist militancy.

This work is a first approach, from memory studies and feminist archives to the feminist struggles for abortion in San Juan. From it, we hope to be able to reconstruct the specificities, not yet portrayed, that the green tide imprinted in San Juan. 
Keywords

Abortion, marea verde, situated feminisms, memory, feminist archives.

\section{Introducción}

En este trabajo nos proponemos rememorar y analizar críticamente las luchas feministas por el derecho al aborto en la provincia de San Juan. Con ello deseamos hacer una aportación a la memoria feminista local desde un punto de vista que es colectivo, situado, parcial, a la vez que atento y respetuoso de los procesos de los que pretende dar cuenta.

La marea verde es el nombre con el que los feminismos de Argentina llamamos a las movilizaciones que aumentaron y se masificaron a partir del año 2018, aunque forman parte de un proceso de expansión feminista que se reconoce en trayectorias previas y de larga data; por ejemplo, en los Encuentros Nacionales de Mujeres (ENM) -hoy también llamados Encuentros Plurinacionales de Mujeres, Lesbianas, Travestis, Trans, No Binaries-, que datan desde 1986 (Alma y Lorenzo, 2008) y que se desarrollan anualmente, en los que sus participantes se reúnen a debatir en talleres y a organizar la agenda feminista del año; en las marchas contra los femicidios, los travesticidios y la violencia de género, convocadas bajo la consigna "Ni una menos", que comenzaron en 2015; en las movilizaciones y paros de mujeres de cada 8 de marzo en el marco del Día Internacional de la Mujer; en las marchas de cada 25 de noviembre, Día Internacional de la Eliminación de la Violencia contra la Mujer.

La marea verde emerge en un periodo signado por políticas de saqueo, endeudamiento y ajuste económico, retroceso de políticas culturales, educativas y sanitarias en el país. Este proceso de inflexión política fue impulsado por el gobierno presidido por Mauricio Macri, quien llegó al poder gracias a la coalición de un sector liberal económico con el partido tradicional centenario Unión Cívica Radical. Macri asumió la presidencia en 2015, tras la reñida derrota del candidato Daniel Scioli, luego de un balotaje. Esto significó el fin de un gobierno de doce años del frente peronista, conocido como kirchnerismo por el apellido de lxs sucesivxs presidentes Néstor Kirchner y Cristina Fernández de Kirchner. ${ }^{1}$ Fue durante el kirchnerismo

1 Para politizar la lectura de este artículo, hemos adoptado el uso de la x como intervención del lenguaje para visibilizar la diversidad sexual y de género. Además, cuando se trata de citas textuales, se incluyen recursos como @, $x,{ }^{*}, e, a / a s$, tal como han sido usados por sus autorxs. Al respecto, entendemos que, en el marco de las luchas feministas y de otras 
que se sancionaron políticas de ampliación de derechos de género y sexualidades, políticas de memoria referidas a los crímenes de lesa humanidad del terrorismo de Estado, así como políticas económicas y sociales favorables a amplios sectores de la sociedad.

Aunque la marea verde es un fenómeno susceptible de ser pensado de modo singular y genérico, está conformado por multiplicidades. Entendemos que los distintos abordajes, principalmente mediáticos, de estas movilizaciones ponen en relieve los sucesos de las grandes capitales urbanas del país, sin detenerse a registrar lo que sucede en la amplia diversidad de los territorios que habitamos. Desde allí construyen una mirada que acentúa ciertos aspectos particulares como si fueran generales y comunes a todas las regiones. Al problematizar estas miradas, nos interesa contribuir a la conformación de una memoria diversa, plural, situada y democrática.

¿Por qué proponer memorias feministas colectivas y situadas? Nos motiva pensar en esta escritura como un diálogo entre nosotras y quienes nos lean: apostamos por y anhelamos un diálogo con aquéllxs que habitan territorios similares al nuestro y, por supuesto, con nuestrxs compañerxs de lucha, coterránexs, aliadxs, con lxs que compartimos mucho más que movilizaciones.

En este territorio, a la orilla de un vasto país, los márgenes son nuestro centro; desde aquí miramos lo que resuena en los centros políticos geográficos y lo resignificamos a la "cuyana", ${ }^{2}$ respondiendo y disputando el significado político de luchas que también son nuestras, pensándolas desde donde pisamos. Son las particularidades, costumbres, dificultades, fortuna fortuita de vivir en las orillas calurosas del oeste argentino las que queremos traer a esta conversación. Porque, si bien muchos de nuestros aprendizajes vinieron de la mano de la lectura, también son producto de innumerables debates en asambleas, reuniones grupales, redes sociales y también bares y festejos. Así, escribimos como un modo de plasmar los debates entre nosotras, como activistas y militantes, sabiendo que, como dice

identidades disidentes, el uso del lenguaje inclusivo implica un posicionamiento político y disruptivo que excede las convenciones lingüísticas.

2 Perteneciente o relativo a la región geopolítica de Cuyo, ubicada en la zona cordillerana y precordillerana del centro oeste de Argentina. 
Elizabeth Jelin (2020), "hay en juego saberes, pero también hay emociones. Y hay también huecos y fracturas" (p. 419).

Además, haber logrado la implementación de un marco legal por el aborto en Argentina -y los debates en diversos países latinoamericanos por la ampliación de derechos para mujeres e identidades sexuales diversas en los últimos diez años- nos posiciona como testigxs y protagonistas de uno de los movimientos sociales más importantes de la historia. Por esto reivindicamos el compromiso, colectivo y horizontal, de compartir debates, estrategias, cuerpo y pasiones con cada feminista convocadx a transformar cada rincón patriarcal.

¿Cómo encaramos esta propuesta? Para construir este punto de vista, hemos realizado una serie de conversaciones feministas en las que ponemos en ejercicio esa memoria que es albergue de historias múltiples y comunes, es decir, compartidas con otrxs. En este ejercicio, vamos elaborando una lectura -o relectura- de una amplia documentación conformada por distintos tipos de archivos que recopilamos de los últimos años de lucha feminista, entre los que se encuentran documentos escritos por organizaciones, declaraciones públicas, comunicados, relatos, entrevistas, así como imágenes gráficas, fotografías y videos. Se trata de archivos referidos a eventos locales y políticos que entendemos inscriptos en la lucha por el derecho al aborto de nuestro territorio.

¿Cuál es nuestro lugar en esta labor? En esas lecturas intervenimos nuestras propias rememoraciones. Es decir, nuestras propias experiencias militantes y activistas colaboran a la composición de esos archivos y nos permiten recuperar sentidos, debates, tensiones y afectos acerca de distintos eventos que no se encuentran registrados físicamente más que en las memorias de quienes los vivenciamos. No obstante, encontrarnos para construir memorias feministas colectivas en San Juan implica reconocer lo procesual, situado y parcial de este archivo y así proponernos el juego de tomar distancia, pero también de dejarnos atravesar nuevamente por cada palabra y gesto.

Así, esta recopilación parte desde nuestros activismos, nuestros recorridos específicos, nuestros saberes como integrantes de organizaciones y agrupaciones como Ni Unx Menos San Juan, ${ }^{3}$ Las Hilarias Socorristas en

3 En marzo de 2021, la asamblea Ni unx Menos San Juan decidió redefinir su logo y lema para reflejar un posicionamiento como sujetxs diversxs. Esta decisión fue publicada en la página oficial de la colectiva con el título "Respecto al cambio de nuestro logo" (Ni unx menos San Juan, 2021). 
Red, la Mesa por el Aborto San Juan, las diversas redes de comunicadoras y periodistas en las que participamos, redes de trabajadorxs de la salud por el derecho a decidir, Espacio de Sociología Feminista(s), entre otras. Nos re-unimos de forma virtual y presencial para entramarnos y entregarnos entre relatos de recuerdos, vínculos, alianzas y decires con el fin de dimensionar la infinita red de relaciones que aparecen en nuestras luchas.

Estos encuentros nos llevaron a reflexionar sobre nuestros múltiples haceres y espacios habitados: académicos, de investigación, de militancia y de activismo feminista. Así, nos permitieron poner en palabras la incomodidad frente a la insistencia de la academia y las instituciones por disciplinarnos en nuestras formas de hacer y producir conocimiento desde una lógica dualista y patriarcal: lo académico/lo activista o militante, lo racional/lo emocional y afectivo, el saber científico/el saber popular. Incomodidad para trascender desde los feminismos, desde las deconstrucciones y autorreflexividad permanentes que nos hacen dimensionar desde dónde nos paramos, cómo, para qué, con quiénes y por qué. Feminismos que nos cuestionan y desde los que cuestionamos distintos relatos y experiencias para evidenciar y poner en tensión las sutiles o grotescas formas en las que el sistema hegemónico patriarcal nos configura el mundo.

Somos compañeras feministas entramadas entre la academia y los activismos feministas. Somos compañeras que venimos de distintas disciplinas y con diversos recorridos que se cruzan insistentemente en cada marcha, actividad, acompañamiento, reunión estratégica y abrazo de lucha. Asumimos y nos reconocemos desde estos posicionamientos políticos, éticos y afectivos. Así, pretendemos recopilar y armar nuestro archivo de lucha para luego animarnos a pensarnos y leernos desde los posibles cruces que nos proponemos como sociólogas, politólogas, comunicadoras sociales y, sobre todo, activistas feministas. Desde aquí, nos re-unimos con el objetivo de tomar, una vez más, la palabra y dejar testimonios de la lucha feminista en San Juan, Argentina.

\section{Feminismos situados en San Juan:}

\section{más allá del discurso oficialista y las miradas centralistas}

San Juan es una provincia ubicada en la zona central oeste de Argentina; junto a las provincias de Mendoza y San Luis, conforma la región de Cuyo. Con una superficie de $89651 \mathrm{~km}^{2}$ y una población aproximada de 681055 habitantes (Instituto Nacional de Estadísticas y Censo [INDEC], 2010), se 
caracteriza por una geografía diversa que va desde el valle serrano hasta la aridez de la zona precordillerana y parte de la cordillera de los Andes, zona que comparte con Chile - ubicado al oeste-. Sus fallas tectónicas la hacen ser una de las zonas con mayor sismicidad en Argentina. Su clima recorre grandes amplitudes térmicas pero, en gran parte del año, predominan las altas temperaturas que llegan a los $40^{\circ} \mathrm{C}$ durante el verano. Aquí, los espacios que habitamos van desde el verde del valle hasta la aridez de alta montaña, desde la ruralidad que marca distancias hasta la urbanidad de una ciudad joven y repleta de nuevas construcciones.

Aquí, entre los últimos fríos de invierno y los calurosos vientos zon$\mathrm{da}^{4}$ que anuncian las nevadas en la alta cordillera, iniciamos estas memorias feministas; con el secano que nos ambienta y entre noticias oficiales que pronostican una de las mayores emergencias hídricas de los últimos años - aunque éstas no aminoran los avances para dar inicio al segundo proyecto megaminero de cobre-oro Josemaría, que implica la explotación de la cordillera andina y sus bienes naturales (Naveda, 2021) - ${ }^{5}$

A continuación, queremos señalar los principales sucesos sociopolíticos e históricos que signaron las luchas locales de mujeres y feministas. Entre ellos, destacamos que San Juan fue la primera provincia de Argentina en donde se aprobó el voto femenino -en 1927- (García, 2001). Militantes feministas sanjuaninas también acompañaron con su participación los primeros Encuentros Nacionales de Mujeres en Argentina, así como encuentros internacionales y latinoamericanos de mujeres, a mediados de los ochenta. En este territorio, las luchas por el derecho al aborto adquirieron gran tenor para la historia local. Además, en esta construcción de memorias, reconocemos a aquellas personas, militantes, activistas y compañeras que aportaron su singularidad a las luchas colectivas; y nos reconocemos

4 Viento que inicia frío y húmedo en el Océano Pacífico, atraviesa la cordillera provocando nevadas en esa zona, y arriba en forma seca y caliente a la zona centro-oeste de Argentina. La llegada del zonda nos anuncia que habrá agua, por lo que la disminución de vientos es preocupante en la actualidad.

5 La megaminería como modelo económico en los últimos años reconfiguró la matriz agro-productiva (basada en la producción de viñedos y olivos) que era propia de esta región. Los proyectos de explotación megaminera a cielo abierto como Veladero, propiedad de la megaempresa multinacional Barrick Gold, ocupan un promedio de 9 millones de litros de agua pura por día. 
en ellas al posicionarnos como parte de las luchas de las mujeres y diversidades en nuestra provincia.

\section{Sufragio femenino provincial en 1927.}

\section{Un antecedente del voto universal en la Argentina de 1947}

Reivindicamos ser parte de la primera provincia en la que las mujeres votamos y fuimos elegidas en el país. En el contexto de la Primera Guerra Mundial, "se produjo una caída considerable de los precios del vino provocando una crisis general de la industria vitivinícola, de central importancia en la provincia, y afectando amplios sectores que vieron comprometidos sus puestos de trabajo" (Iturrieta y Sillero, 2021, p. 3). En 1923, la falta de respuesta de los gobiernos tradicionalistas de la oligarquía provincial generó las condiciones para el ascenso de Federico Cantoni a la gobernación. ${ }^{6}$ El cantonismo no implicó una revolución, pero moderó el liberalismo feroz e intervino estatalmente con políticas económicas en favor de los sectores medios y populares que lo apoyaban (Ramella, 1985, citado en Iturrieta y Sillero, 2021, p. 4).

En este contexto, en 1927 se llevó a cabo una reforma constitucional que, entre otras políticas sociales y de redistribución económica, institucionalizó el voto femenino en San Juan (Henríquez, 2007; García et al., 2009). El sufragio femenino estuvo basado en el mantenimiento de la diferencia, es decir, "en las características particulares atribuidas a las mujeres como cuidadoras de los miembros de la familia y administradoras del hogar" (Iturrieta y Sillero, 2021, p. 4). No obstante, significó la igualdad en términos de ciudadanía política al permitir, por primera vez en la historia del país, la candidatura y el sufragio de las mujeres como un derecho político y ya no como un privilegio de ciertas mujeres de las clases dominantes

6 "El recambio de sectores dirigentes que se expresa en el cantonismo, manifiesta la emergencia de nuevos grupos industriales - no vinculados directamente a la actividad vitivinícola-, la adhesión de grupos tradicionales desplazados - fundamentalmente antiguos sectores ganaderos y cerealeros, excluidos del modo de inserción provincial al proyecto económico delineado a partir del ochenta- y la reconfiguración de los sectores subalternos. Este movimiento implica, a la vez, una redefinición del posicionamiento de las familias que, a lo largo de la historia sanjuanina, se disputan el predominio en el espacio social; en este sentido, los gobiernos cantonistas expresan el avance de familias de reciente ingreso al país, la provincia y el campo político" (Gómez y Goldberg, 2013, p. 61). 
que sólo podían ejercerlo en su condición de propietarias (Ramella, 1985; García, 2001; Iturrieta y Sillero, 2021).

Así, en 1928, Emilia Collado fue electa intendenta de Calingasta, y Emar Acosta, abogada sanjuanina de origen riojano, se convirtió en la primera mujer en acceder a una banca legislativa en la provincia, en el país y en América Latina (Salcedo, 2018). Cerca de veinte años después, en 1947, durante el gobierno de Juan D. Perón, se instituyó el voto universal que reconoció los mismos derechos políticos a todas las personas mayores de dieciocho años de Argentina. En las elecciones de 1951, cerca de la mitad del padrón electoral nacional estaba conformado por mujeres. Ese año, $90 \%$ de las electoras empadronadas participaron en los comicios (Valobra, 2008, p. 57). Además, la asignación de cuotas internas en el Partido Justicialista permitió que más del $30 \%$ de las candidatas propuestas (veinticuatro diputadas y nueve senadoras) llegaran a ocupar escaños en ambas cámaras del Congreso nacional (Barrancos, 2014, p. 24).

\section{Movimientos de mujeres y de feministas tras el último retorno democrático}

En nuestra genealogía, también reconocemos a Esther Shneider y a Clara Carvajal, madres de Plaza de Mayo de San Juan. Ellas mantuvieron viva la lucha por la verdad y la justicia durante y después de la última dictadura militar (1976-1983), junto a otras madres y abuelas de desaparecidos y víctimas de centros clandestinos de detención.

La dictadura de 1976 irrumpió en nuestra historia de manera brutal. Los trabajos de memoria que hoy hacemos intentan recuperar aquellas luchas sabiendo que no contamos con documentación y que, incluso, muchos recuerdos fueron borrados junto a las personas asesinadas y desaparecidas.

Reconocemos a nuestras antecesoras, entre ellas a Lucy Collado, para quien queremos hacer un especial homenaje. Lucy Collado, feminista incansable y hermana de todas nosotras, nos marcó caminos con su ejemplo y su guía. Nació en San Juan, en donde se recibió de maestra. Ejerció la docencia en Mendoza en las décadas de los cincuenta y sesenta, y luego en Buenos Aires. Fue militante del Partido Socialista; posteriormente se centró en la lucha por los derechos de las mujeres vinculándose al movimiento feminista. La desaparición de su sobrino, en la dictadura cívico-militar del 76, la marcó profundamente y se unió a la lucha de las madres y familiares de 
desaparecidos. Además, fue integrante de la Asociación Permanente por los Derechos Humanos (APDH) de San Juan. Fue ampliamente reconocida dentro del movimiento de mujeres a nivel regional y nacional. ${ }^{7}$

Su hermana Rosa Collado y otras más de veinte mujeres sanjuaninas viajaron a Buenos Aires en agosto de 1975 en respuesta a la convocatoria feminista para la conformación de la Coordinadora Argentina por el Año Internacional de la Mujer. En octubre llevaron a Berlín las conclusiones de la Coordinadora (R. Collado, Comunicación personal, 15 de abril de 2018). ${ }^{8}$

En el mismo año surgió el Congreso Nacional Decenio de la Mujer. Como parte de sus iniciativas para ese periodo, en 1984 se conformó la Multisectorial de la Mujer Sanjuanina. Este espacio se extendió a todo el país en el periodo posterior a la dictadura (R. Collado, Comunicación personal, 15 de abril de 2018).

Llevamos en nuestro legado a otras pioneras de este periodo histórico: las feministas sanjuaninas Silvia Prolongo y Adela "Morocha" Carvajal. Ellas nos recuerdan que

El primer feminismo sanjuanino surge en un completo desierto. La primera actividad fue que nos constituimos en una multisectorial de la mujer, con mujeres de distintos partidos políticos. Luego participamos en el primer Encuentro Nacional de Mujeres en Buenos Aires. (Ávila, 2018, p. 45)

A partir de esa experiencia, constituyeron la Asociación Sanjuanina de Estudios de la Mujer (ASEM), cuyo objetivo fue, en palabras de "Morocha" Carvajal, "tomar conciencia de las cosas que nos habían pasado enmarcadas en la sociedad patriarcal" (Ávila, 2018, p. 45). Prolongo y Carvajal recuerdan este espacio como uno "no muy concurrido" pero sí de "fraternidad y contención del dolor por las cosas que habíamos pasado" (Ávila, 2018, p. 45). Relatan que, a pedido de Ursulina Cantoni, quien ocupaba la Secretaría de la Mujer, se creó la Cátedra de la Mujer en la Facultad de Ciencias Sociales y después el Programa de Desarrollo de Estudios de la Mujer (ProDeM).

7 Para más información, véase Agencia FARCO (2016).

8 Entrevista a Rosa Collado realizada por Dolores Córdoba (Archivo personal). 


\section{Los encuentros de mujeres en San Juan}

Estamos acá porque también traemos con nosotras las experiencias, las discusiones y los lazos que hemos construido entre todas en los ENM. El activismo de mujeres tiene en nuestra provincia una historia ligada a la lucha por los derechos sexuales, reproductivos y no reproductivos (Brown, 2011), que tiene como hito el XII Encuentro Nacional de Mujeres de 1997. Este encuentro posicionó las demandas feministas en el ámbito de lo público en el marco de una fuerte disputa con actores estatales y de la Iglesia católica que se oponían a la realización del evento en la provincia. El eje de dicha agenda es, desde hace varios años, el derecho al aborto, quizás como paradigma de la desobediencia a la heterosexualidad como régimen político y el mandato reproductivo concomitante.

Perla Welner, referente del Movimiento de Mujeres Sanjuaninas y una de las mujeres que participó en esas luchas, denunciaba que:

Ningún legislador levanta la voz. Esta Legislatura sigue con la postura de que sobre este tema no se habla. [...] A último momento, cuando ya más de diez mil mujeres se encontraban en la provincia, sale la cúpula de la iglesia y parte del gobierno, en ese entonces el gobernador Escobar, impulsando un encuentro paralelo protagonizado por Rosalía Garro ${ }^{9}$ y el padre Lona. Rosalía Garro nos plantea que no se abrieran talleres sobre aborto, que no se hablara sobre divorcio, que fuera acotado a lo que le parecía. Como rechazamos [ese planteo] nos quitaron el apoyo. (Ávila, 2018, p. 46)

Fueron militantes sanjuaninas quienes realizaron el XII Encuentro Nacional de Mujeres en nuestra provincia pese a las presiones del gobierno, la Iglesia católica y sectores conservadores que se oponían al mismo. Al no lograr impedir el encuentro, se propusieron boicotearlo realizando un encuentro paralelo y agrediendo a los contingentes de mujeres que viajaron hacia la provincia. A pesar de todos los obstáculos, el ENM se realizó y cerca de diez mil mujeres pudimos participar y debatir en los talleres (Ávila, 2018).

9 Militante del Partido Justicialista, maestra, expresa política. Fue funcionaria provincial en la Subsecretaría de la Familia del Ministerio de Desarrollo Humano. 
Lucy Collado, feminista sanjuanina y miembro de la Comisión Organizadora de los dos encuentros realizados en la provincia, declaró al diario Clarín: "Nos dicen subversivas porque debatimos sobre sexualidad, anticoncepción, religión y otros temas" (Clarín, 1997). Es interesante la recuperación del término "subversivas" que hace Lucy, una de las feministas con mayor trayectoria en San Juan, fallecida en marzo de 2016. Lucy perteneció al Movimiento de Mujeres Sanjuaninas, con manifiestas diferencias por la alineación partidaria de ese movimiento. Era maestra y militante, feminista y luchadora por los derechos humanos. Vivió la dictadura y luchó por la memoria, verdad y justicia. Fue miembro de la APDH. Con un sobrino desaparecido, sabía lo que la acusación de subversivas significó en nuestro país. Sabía también que subvertir el orden de género era y es necesario (R. Collado, Comunicación personal, 15 de abril de 2018).

En 2013, San Juan fue la sede del XXVIII Encuentro Nacional de Mujeres; era su segunda vez en la historia de estos encuentros. En esta ocasión, se realizó por primera vez el taller de Mujeres Travestis y Trans, un espacio de reconocimiento y lucha que hacía años se pedía que fuera incluido formalmente por la Comisión Organizadora de los encuentros para visibilizar que "la discriminación a las mujeres trans es violencia de género" (Araya en Toledo, 2021). ${ }^{10}$ Reconocemos estos recorridos porque evidencian los distintos ciclos de la lucha por los derechos de las mujeres e identidades sexuales diversas. Derechos que han sido durante mucho tiempo invisibilizados por parte de la sociedad.

El ENM posibilitó un semillero de agrupaciones y organizaciones feministas en la provincia. Sin embargo, también intensificó las formas discursivas que desde espacios de poder patriarcal constituyen el ideario de un San Juan homogéneo, conservador y tradicional, tratando de borrar las diversas disidencias y luchas por la ampliación de derechos.

\section{La marea verde local y las tensiones centro-provincia}

Nos reconocemos como testigxs y protagonistas de esta época particular. Aquí, apostamos por una memoria feminista colectiva y necesariamente situada porque desde sus inicios nuestro país evidencia una tensión

10 Verónica Araya es una referente de la Asociación de Travestis Transexuales y Transgéneros de Argentina (ATTTA) en San Juan. 
permanente entre una mirada más centralista y otra más federal y atenta a los proyectos políticos locales.

Un ejemplo de lo anterior fue la persistente dificultad para establecer representaciones provinciales y orgánicas dentro de la Campaña Nacional por el Derecho al Aborto Legal, Seguro y Gratuito (en adelante, Campaña Nacional). También se lograron generar diversas redes de periodistas y comunicadoras que, al no articular sistemáticamente con la Campaña Nacional, desarrollaron diversas producciones, campañas e intercambios a favor de la legalización del aborto y con interés en promover la perspectiva federal. Reconocemos, también dentro de los feminismos, cierta tendencia "centralista" cuyo centro es Buenos Aires y, con suerte, otras ciudades metropolitanas del país, tales como Córdoba, Santa Fe y Mendoza. Esa tendencia abona a una construcción que se ciñe a la mirada de un "interior" - conformado por el resto de las provincias- considerado atrasado e impotente.

Las tensiones mencionadas adquieren mayor relevancia, a la vez que admiten otros sentidos, con las particulares dinámicas de lucha que se plantearon durante el año 2018 desde ciudades más pequeñas como San Juan. Durante ese año, los activismos locales se organizan en torno al primer debate y tratamiento del Proyecto de Ley de Interrupción Voluntaria del Embarazo que tuvo lugar en la Cámara de Diputados y de Senadores (Chousal Lizama, 2020). ${ }^{11}$ Entre junio y agosto, diversas redes y organizaciones feministas de Buenos Aires entraron en contacto con redes y organizaciones feministas de las provincias para coordinar acciones, actividades, así como estrategias que pudiesen poner en agenda pública el debate. El objetivo de estas tácticas era incidir en lxs representantes legislativxs de cada provincia.

En estos intercambios, se manifestaban fuertes diferencias en cuanto a las formas de organización, toma de decisiones, ritmos y dinámicas de trabajo, priorización de estrategias, tonos, los tipos de públicos y abordajes posibles. De estas articulaciones entre Buenos Aires y las provincias, sumado a que el proyecto fue rechazado en el Senado, el gusto que nos quedó fue amargo.

11 El proyecto se presentó seis veces anteriormente y en varias ocasiones perdió estado parlamentario. En cada ocasión, fue presentado por la Campaña Nacional por el Derecho al Aborto Legal, Seguro y Gratuito (véase Campaña Nacional por el Derecho al Aborto Legal, Seguro y Gratuito, s. f.). 
Luego de esta experiencia, fue necesario tomar distancia, plantearnos debates en clave de balance para poder pensar articulaciones mucho más estratégicas y consolidar redes que realmente dieran cabida a las diversas idiosincrasias y territorios. En este sentido, nos propusimos establecer más y mejores formas de vincularnos inter-provincialmente, basadas en la confianza, el cuidado y el reconocimiento, no solamente entre lxs diversxs compañerxs sino teniendo en cuenta las procedencias, zonas, regiones y territorios.

La tensión entre capital y provincia en la Argentina tiene historia, memoria y reactualización. En San Juan existe el pensamiento feminista, pero es necesario repensarlo, problematizarlo y redimensionarlo de acuerdo con nuestro contexto histórico-social. Sobre todo, para no repetir discursos colonialistas que obturan el debate al considerar a la provincia desde el atraso, el conservadurismo, bajo la idea de que siempre estamos igual y nada cambia. Aquella metáfora que identifica y reconoce el "interior" de Argentina con una esencia inmutable y sin las activistas repensándonos desde otros lugares posibles no es real.

\section{Políticas de género en San Juan; \\ hechas de omisiones e incumplimientos}

Interesa, por otro lado, identificar nuestro contexto situacional a partir de la descripción del estado de políticas públicas específicas. La provincia de San Juan, junto a otras regiones del país (sobre todo del noroeste de Argentina), se caracteriza por la no aplicación de normas fundamentales de los derechos sexuales, reproductivos y no reproductivos. La irregular aplicación del Programa Nacional de Salud Sexual y Procreación Responsable, la postergación de doce años para la adhesión a la Ley N ${ }^{\circ} 26.150$ sobre educación sexual integral y de nueve años para la adhesión a la Ley N. ${ }^{\circ} 26.485$ contra la violencia de género exponen las resistencias al reconocimiento y ampliación de derechos desde los diversos gobiernos provinciales de San Juan (Córdoba et al., 2019).

En 2006, los movimientos de mujeres y feministas sanjuaninos denunciamos al entonces ministro de Salud -hoy secretario técnico del mismo ministerio- cuando dio la orden de que no entregaran los anticonceptivos intrauterinos, también llamados DIU (Carbajal, 2006b). En la provincia, se creó en 2003 el Programa de Salud de la Mujer, nombre que se dio a la versión local del Programa Nacional de Salud Sexual y 
Procreación Responsable, desde el cual debían ser entregados en hospitales y centros de salud los anticonceptivos enviados desde el gobierno federal. En 2006, el secretario de Salud del gobernador Gioja se negó a entregar los dispositivos intrauterinos provistos por el Programa Nacional, lo que resultó en protestas del movimiento de mujeres y académicas feministas, reflejado en medios de comunicación nacionales. Frente a esto, las acciones desarrolladas desde el Movimiento de Mujeres de San Juan lograron restablecer el Programa de Salud Reproductiva, aunque sin DIU (Carbajal, 2006a).

Como activistas y académicas, podemos decir que las feministas sanjuaninas luchamos junto al movimiento LGBTQI de San Juan y del país por la ley de matrimonio igualitario en 2010 y la ley de identidad de género en 2011. También, en esta ocasión, pese a los embates de los sectores políticos conservadores y la Iglesia católica; éstos llegaron al extremo de desarrollar campañas en contra, con el apoyo de la gobernación, para movilizar a alumnxs de escuelas públicas y privadas bajo la consigna de "queremos mamá y papá" (Gimeno, 2018, p. 35).

En 2012, la Corte Suprema de Justicia de Argentina se pronunció sobre los alcances del marco jurídico sobre el aborto, vigente desde 1921 como una excepción o permisión a la norma penal de aborto para aquellos casos de embarazos producto de una violación y para los casos en los que el embarazo implicara un riesgo para la vida o la salud de la gestante. A raíz de una situación de aborto por violación y ante las dificultades recurrentes a lo largo del país para acceder a un aborto no punible, la Corte estableció el fallo "F., A. L. s/ medida autosatisfactiva"; en él exige "al Poder Judicial nacional y a los poderes judiciales provinciales y de la Ciudad Autónoma de Buenos Aires a abstenerse de judicializar el acceso a los abortos no punibles previstos legalmente" (Corte Suprema de Justicia de la Nación [CSJN], 2012, pp. 30-31). Además, exhorta "a las autoridades nacionales y provinciales a implementar y hacer operativos, mediante normas del más alto nivel, protocolos hospitalarios para la concreta atención de los abortos no punibles a los efectos de remover todas las barreras administrativas o fácticas al acceso a los servicios médicos" (CSJN, 2012, p. 27).

Tras el fallo, el Ministerio de Salud de la nación argentina desarrolló en 2015 el "Protocolo para la atención integral de las personas con derecho 
a la interrupción legal del embarazo", conocido como Protocolo ILE. ${ }^{12}$ Sin embargo, hasta la aprobación de la ley IVE en diciembre de 2020, San Juan permaneció como

una de las cinco [provincias] del país donde no existía adhesión a políticas públicas nacionales ni elaboración de políticas provinciales para garantizar la atención a personas que soliciten abortos legales [...] y donde hasta comienzos de 2021 se mantiene una ley que prohíbe la venta de misoprostol en farmacias, medicamento utilizado para provocar abortos voluntarios. (Iturrieta, 2021a, párr. 4) ${ }^{13}$

Fue en el marco de los debates por el aborto legal en 2018, y a partir del estado público que alcanzaron diferentes requerimientos de aborto enmarcados en la ley, que adquieren resonancia los problemas de acceso a la ILE en la provincia. En ese entonces, el acceso a la ILE fue posible tras la presión social local, la difusión de los casos, incluso a nivel nacional, y, especialmente, por el trabajo de redes de organizaciones feministas y de trabajadorxs de la salud comprometidxs con los derechos humanos, el acceso a la salud y a favor del derecho a decidir.

Vale decir que la difusión de estas situaciones trajo nuevamente debates y tensiones entre feministas locales -y entre feministas locales y feministas de otras regiones - en torno a si era conveniente y, más aún, ético, visibilizar cada suceso. Por un lado, los medios hegemónicos locales publicaban notas escabrosas sobre la vida y entorno social, económico, familiar de las solicitantes de aborto. Por otro lado, algunos sectores feministas locales y de otras provincias demandaban de forma insistente a las redes feministas y de profesionales que acompañaban estas situa-

12 Este documento actualizó la Guía Técnica para la Atención Integral de los Abortos No Punibles elaborada en 2010 (Ministerio de Salud de la Nación, 2010).

13 Luego de sancionada la ley IVE, se emitió un "Comunicado de Salud Pública de la provincia dirigido a farmacias y droguerías a finales del mes de marzo para habilitar el expendio de misoprostol, sujeto a prohibición por la Ley 1133 Q desde 2012. [Sin embargo,] en el Digesto Jurídico de San Juan la Ley 1133 Q figura en vigencia. No se ha publicado resolución alguna referida a esta situación en el Boletín Oficial del Gobierno de San Juan, ni en ningún medio oficial" (Iturrieta, s. f.). 
ciones conocer y poder dar a conocer por distintos medios lo que estaba sucediendo.

Frente a esto, algunas de las interrogantes que nos interpelaban apuntaban a la definición de las estrategias de comunicación: ¿acaso son todas válidas?, ¿todo es comunicable?, ¿quién decide lo que se comunica?, ¿cómo se hace y en qué momento?, ¿qué pasa si la visibilización de un caso dificulta el acceso al derecho?, ¿qué pasa cuando las denunciantes quieren difundir o cuando no quieren pero las feministas consideran que hay que hacerlo? Las estrategias discursivas en estos momentos no siempre son consensuadas con las personas implicadas y su entorno. Más bien, son el resultado de pujas de poder que se disputan el contenido, la forma y el tiempo de lo que será comunicable.

En 2018, el debate legislativo tuvo lugar en -y en gran medida gracias a- esta época feminista que mencionamos in crescendo desde 2015. Esto posibilitó la participación de numerosas voces en el espacio público provincial, que pudieron exponer las ausencias de políticas locales específicas y los incumplimientos con las políticas nacionales en vigencia referidas a derechos de mujeres e identidades sexuales diversas, situación que sólo había sido problematizada por un público reducido. Así, ante la puesta en agenda en los medios nacionales, los medios de comunicación hegemónicos en San Juan reflejaron el debate en el Congreso y dieron cabida, aunque de forma acotada, a los movimientos feministas de la provincia.

Pese al rechazo legislativo de la ley IVE, los incumplimientos del gobierno provincial permanecieron bajo la lupa. Recién en noviembre de 2018, la Cámara de Diputados de la provincia de San Juan votó a favor de la adhesión y reglamentación provincial de la Ley N. ${ }^{\circ} 26.485$ de protección integral a las mujeres. Hasta entonces, había mantenido una ley provincial que circunscribía la violencia al ámbito familiar y no reconocía la especificidad de la discriminación de géneros como fundamento de la violencia contra mujeres y diversidades sexuales. Es decir que la ley provincial funcionó como un mecanismo estatal para obstruir la plena adhesión y aplicación de una ley fundamental como la Ley N. ${ }^{0}$ 26.485. En este mismo periodo, también se votó la adhesión provincial a la Ley N. ${ }^{\circ} 27.499$ -más conocida como ley Micaela- de capacitación obligatoria en la temática de género y violencia contra las mujeres para todas las personas que se desempeñaran en la función pública. 
Entendemos que estas adhesiones provinciales fueron posibles en el marco de los debates públicos de ese año, que argumentaron contra la negación de derechos a mujeres e identidades sexuales diversas. Sin embargo, estas adhesiones a marcos legales todavía carecen de presupuestos y políticas públicas locales integrales que den respuestas a las numerosas denuncias de mujeres e identidades sexuales diversas por situaciones de violencia de género.

Por último, un punto significativo es que San Juan, junto a Salta, fueron las dos únicas provincias del país en donde el rechazo a la ley IVE en el año 2018 fue absoluto. Todxs lxs legisladorxs, tanto en la Cámara de Diputados como en la Cámara de Senadores, votaron unánimemente en contra del proyecto (Córdoba y Domínguez, 2019).

A finales de 2019, hubo elecciones presidenciales y resultó electo el frente opositor al macrismo, que se había comprometido en campaña a avanzar con la legalización del aborto. Pero el año 2020 inició con una situación global de pandemia y su consecuente crisis sanitaria y económica. No obstante, el descontento de los feminismos tras el rechazo de 2018 supo transformarse en estrategias de acción política en un contexto difícil. Quizás por eso mismo una conquista colectiva, como lo fue la aprobación de la ley IVE presentada por el Poder Ejecutivo nacional, significó una alegría para un amplio sector de la sociedad que venía protagonizando las movilizaciones masivas de los últimos años y, por ende, disminuyó cierta presión social sobre la clase dirigente.

Como mencionamos, la ley IVE fue presentada por el Poder Ejecutivo, cuyo sector político es el mismo que el Ejecutivo provincial y la mayoría de representantes provinciales, lo que, sin duda, significó una influencia a la provincia desde el gobierno federal. No obstante, sólo un diputado nacional de representación provincial votó a favor de la ley IVE; en el Senado, todxs lxs representantes de San Juan volvieron a votar de forma unánime en contra. Sin embargo, el voto positivo del diputado fue bien recibido por parte de los feminismos que, tras años de insistencia ante la clase política, tomaban el suceso como un triunfo y un reconocimiento a los esfuerzos colectivos de años de lucha.

Para concluir este apartado, queremos decir que muchas de las organizaciones feministas de San Juan, entre ellas las agrupaciones que articulamos en la colectiva Ni Unx Menos San Juan y colectivas como Las Hilarias Socorristas en Red, nos reconocemos en esta memoria que trasciende 
generaciones. Y así, también, nos reconocemos hijas del XXVIII Encuentro Nacional de Mujeres, el evento más reciente que marcó un hito histórico para el movimiento feminista en San Juan. Este encuentro convocó a más de 20 mil participantes de todo el país y de Nuestramérica (Ávila, 2018). Además, muchas mujeres jóvenes se sumaron a la Comisión Organizadora en la previa del encuentro y, tras su realización, surgieron diferentes colectivas feministas que dieron un nuevo ímpetu al movimiento local. En suma, y como compartiremos a continuación, este ENM fue de gran importancia para nuestra historia local y feminista.

\section{Estrategias feministas por el aborto en San Juan}

A continuación, a partir de la elaboración de un archivo de memorias feministas locales compuesto por declaraciones públicas, comunicados, relatos, entrevistas, imágenes gráficas, fotografías y videos, distinguimos tres momentos en las luchas por el aborto en San Juan.

Un primer momento, antes de 2013, en el que los debates se dieron conjuntamente en la universidad -impulsados por académicas militantes$\mathrm{y}$ al interior de algunas organizaciones sociales. En este periodo, el activismo en las calles estaba ligado principalmente a las marchas por el matrimonio igualitario y a las luchas socioambientales.

Un segundo momento se dio en 2013 a partir del ENM, cuando las luchas por la legalización del aborto adquirieron mayor notoriedad en las calles. Las demandas de algunas colectivas, principalmente de aquéllas surgidas al calor del encuentro, se expresaron en manifestaciones públicas y pusieron en discusión la agenda de los feminismos en San Juan.

Un tercer momento, que ubicamos a partir de 2018, cuando el Congreso de la Nación abrió el debate por la legalización del aborto. En este momento, la cuestión del aborto adquirió un carácter público inédito hasta entonces; ocupó espacios en los medios de comunicación, en las universidades y en las movilizaciones sociales. Además, en este tercer momento, las organizaciones locales comenzamos a darnos espacios de articulación sostenidos y a diagramar nuestra propia agenda política feminista local.

Por último, incluimos un cuarto momento para dar cuenta de los saldos de la marea verde tras el rechazo de la ley de aborto en 2018, que no son asimilables a las dinámicas organizativas de ese año pero recogen los aprendizajes de ese periodo. 
Una aclaración reiterada pero necesaria nos obliga a dar cuenta de que el registro que recuperamos es parcial e interesado. Se compone de piezas en las que de algún modo hemos intervenido, ya sea en su producción, como testigxs de su época o, cuando menos, en su actual selección para nada casual. Son los registros que tenemos a mano por nuestra participación en organizaciones sociales, militantes y estudiosas de la cuestión del aborto y los feminismos en San Juan. Hemos intentado recorrer distintas páginas digitales de organizaciones, colectivas feministas, portales digitales de comunicación. Sin embargo, aunque no creemos que sea posible componer un archivo en su totalidad, no hemos realizado un trabajo exhaustivo sino más bien hemos ensayado un punto de partida para un proceso de memoria en construcción que nos permita dialogar sobre nuestras luchas con compañerxs feministas.

A continuación, abordaremos y rememoraremos los eventos que consideramos significativos en la lucha por el aborto. Intentamos reconstruir los debates y tensiones, así como las estrategias que llevan adelante las organizaciones y grupos locales. Nos resulta necesario tener en cuenta, en algunos momentos más que en otros, la relación entre las organizaciones de San Juan, así como la relación entre éstas y las organizaciones de las grandes ciudades del país, como las de Buenos Aires.

Asimismo, buscamos identificar cuáles son los medios en los que se producen las discusiones. Si se trata de posicionamientos organizacionales que se difunden públicamente, si se debaten en espacios como asambleas o si operan en torno a un documento o declaración. En suma, intentamos identificar posiciones, actorxs, formas de tomar posición y sus efectos y repercusiones parciales.

\section{Primer momento: entre las calles y la universidad}

Antes del ENM de 2013, las organizaciones y grupos feministas se movían entre la necesidad de un espacio propio de mujeres y la de debatir con compañeros varones sobre sus demandas, reivindicaciones e intereses políticos. Esto puede observarse en grupos como Insumisas, ${ }^{14}$ un taller de lectura y debate integrado sólo por mujeres que, a su vez, pertenecían a otros

14 Estas reflexiones son desarrolladas aquí por Yanina Iturrieta, quien formó parte del grupo Insumisas. 
espacios como el Centro Cultural El Barro o el partido político Movimiento Socialista de los Trabajadores (MST), en los que participaban varones. A partir de esos talleres de mujeres, este grupo produjo una convocatoria para un 8 de marzo, Día Internacional de la Mujer Trabajadora, evento al que asistieron compañeros y compañeras de distintos espacios a debatir sobre temáticas de género y sexualidad.

En estas primeras manifestaciones, la consigna "este cuerpo es mío" era la más recurrente. El cuerpo de referencia era el de la mujer, sujeto predilecto del feminismo y los movimientos de mujeres, y hasta entonces poco discutido. Vale aclarar que, en ese momento, eran pocas las organizaciones que se posicionaron desde el feminismo.

Así, varias integrantes de espacios mixtos buscamos ámbitos sólo de mujeres; no como un lugar único de participación, sino como un lugar o refugio en donde compartir vivencias y reflexiones necesarias para desnaturalizar las violencias propias en un ambiente de cuidado y respeto. Posteriormente, trasladamos aspectos de estos debates a espacios compartidos con varones.

Entendemos que en todo espacio político se disputa su orientación y posicionamientos frente a diversas temáticas. Esas disputas son dadas por sujetos con diferentes posiciones y recursos desiguales, lo que hace que no todos tengan la misma capacidad de imponer su punto de vista. Así, el espacio de mujeres funciona como un ámbito de problematización, ideación y fortalecimiento que permite a sus participantes encarnar luego esos debates desde otras posiciones políticas, subjetivas y corporales.

Estos sentidos y posiciones también fueron registrados en uno de los boletines de Insumisas, producido en el año 2011, que propone debatir en torno a tres ejes: 1. educación sexual para decidir, 2. anticonceptivos para no abortar y 3. aborto legal para no morir y embarazos y partos en el modelo médico hegemónico (Insumisas, 2011). La consigna de la Campaña Nacional es reproducida en su totalidad y ampliada en su tercer punto, que incluye tanto eventos reproductivos como no reproductivos, es decir, embarazos, partos y abortos. No obstante, en esos momentos no existía una comunicación desde las organizaciones locales con la Campaña Nacional; lo que sucedió fue una apropiación y resignificación de estas consignas con el propósito de reinstalar la discusión sobre el aborto en San Juan.

El 2012 fue un parteaguas para gran parte de las regiones del país. Como mencionamos anteriormente, ese año la CSJN emitió un fallo aclaratorio que estableció los términos en los cuales se debe garantizar el de- 
recho al aborto no punible, de acuerdo con las tres causales previstas en el artículo 86 del Código Penal. Además, estableció las obligaciones de las autoridades nacionales y provinciales para viabilizar el acceso al aborto en las circunstancias que lo admiten, sin interponer obstáculos judiciales, administrativos o de ningún otro tipo (CSJN, 2012).

No obstante, en la provincia de San Juan, este fallo no se tradujo en el acceso a abortos no punibles. Aunque sí aportó nuevas herramientas para problematizar la cuestión del aborto: ya no se trata solamente de un problema de restricciones legales, sino de un problema de accesibilidad que afecta especialmente a quienes habitamos en territorios en donde los gobiernos provinciales no reconocen ni se adhieren a marcos legales establecidos por el Poder Ejecutivo y el Poder Judicial de la Nación.

En mayo de ese año, el Equipo de Investigación en Género y Ciudadanía de la Facultad de Ciencias Sociales de la Universidad Nacional de San Juan (FACSO-UNSJ), junto al Programa de Desarrollo de Estudios de la $\mathrm{Mu}-$ jer (ProDeM) ${ }^{15}$ y el Instituto Nacional contra la Discriminación, la Xenofobia y el Racismo (INADI) convocaron a la mesa redonda "Fallo de la CSJN, Aborto no punible y Políticas Públicas de las Mujeres", que se realizó en la FACSO. En la mesa participaron Claudia Anzorena, miembro de la Campaña Nacional e investigadora en políticas públicas de las mujeres de la provincia de Mendoza, Silvia Prolongo, feminista sanjuanina y fundadora del ProDeM, y el entonces delegado del INADI, el abogado Horacio Rodríguez. Se trató de un evento primordialmente académico, en el que participaron militantes y activistas locales (Córdoba, Comunicación personal, septiembre de 2021).

En ese mismo año, también se realizan las Jornadas Nacionales de Historia de las Mujeres, organizadas por la Asociación Argentina para la Investigación en Historia de las Mujeres y Estudios de Género (AAIHMyEG). Tuvieron lugar en la FFHyA de la UNSJ en el mes de septiembre. La Campaña Nacional se hizo presente con un panel de debate en el que expositorxs de distintos lugares del país - ningunx de San Juan- compartieron sus trabajos; la campaña organizó, además, otras actividades extracadémicas (Comité Organizador, 2011). Estos espacios de apertura para el debate y las discusiones, entendemos, anticiparon un 2013 feminista en la provincia.

15 Desarrollado también en la FACSO. 
Por último, señalamos algunas reflexiones. Por un lado, destacamos que en la provincia se recuperaron las consignas de la Campaña Nacional; sin embargo, no existía una participación local dentro de esta articulación nacional. Por otro lado, podemos decir que, mientras los grupos locales como Insumisas elaboraron acciones y boletines para difundir debates y posicionamientos políticos entre militancias, estudiantes y un público más amplio, la Campaña Nacional y la AAIHMyEG desarrollaron jornadas académicas; de hecho, se editó una compilación de artículos de investigación sobre aborto con las ponencias de las jornadas: El aborto como derecho de las mujeres. Otra historia es posible (Zurbriggen y Anzorena, 2013), que tuvo gran trascendencia entre investigadorxs y académicxs feministas.

\section{Segundo momento: hijas de los encuentros}

El 2013 marcó un segundo momento en la lucha local. Ese año, San Juan fue sede por segunda vez de un Encuentro Nacional de Mujeres.

Antes de dicho evento, un grupo de organizaciones y mujeres activistas no agrupadas en partidos políticos elaboramos un folleto (Centro Cultural El Barro et al., 2013) con el que invitamos a participar en el encuentro. A la vez, en el folleto expusimos las siguientes ideas sobre temas de la agenda de mujeres y de género: 1. la denuncia de la minería a gran escala, el saqueo económico y la explotación de los bienes comunes naturales, que conforman un enclave de explotación territorial y de los cuerpos que lo habitan, cuyas condiciones de vida se ven deterioradas; 2 . la denuncia de inaplicación de la ley de educación sexual integral; 3. el reclamo en torno al derecho a la salud sexual y reproductiva, con énfasis en el uso de métodos anticonceptivos y en la desigual repartición de responsabilidades en la pareja heterosexual a favor de los varones y en detrimento de las mujeres; 4 . el reclamo de implementación de protocolos de aborto no punibles en la provincia; 5. la implementación de la Ley 26.485 de protección integral a las mujeres, negada bajo la excusa de que resultaba inútil en una provincia que ya contaba con una Ley Provincial sobre Violencia Familiar - sin perspectiva de género y limitada a las violencias en el ámbito privado del hogar- (Centro Cultural El Barro et al., 2013).

Las autoras del folleto nos posicionamos como mujeres y hablamos sobre problemas de mujeres. Sin embargo, al reclamar la implementación de la educación sexual integral (ESI), también incluimos a otros sujetos de 
derechos, aunque sin nombrarlos explícitamente. A continuación, presentamos un fragmento de este texto:

Quienes no formamos parte de esa idiosincrasia denunciamos este accionar negligente, así como el incumplimiento de las funciones que corresponden a nuestr@s representantes, que hacen caso omiso de los reiterados reclamos de estudiantes, docentes y organizaciones.

Si bien hoy gran parte de nuestra sociedad reproduce esta lógica invisibilizando otras prácticas y experiencias, por más que intenten ningunearlas o reprimirlas, existen para plantear una educación liberadora, a través de las cuales nos construimos sujet@s íntegr@s, capaces de construir relaciones igualitarias y respetuosas con nosotr@s mism@s, nuestros cuerpos y con 1@s demás. (Centro Cultural El Barro et al., 2013)

Por otro lado, en el texto se presentó una lectura acerca de la sociedad sanjuanina, entendida en su carácter múltiple y conflictivo. Sobre esto, se denunció que "la Iglesia católica y los altos mandos de gobierno" pretenden figurar un imaginario de sociedad homogéneo con características definidas como conservadurismo y basada en la moral cristiana (Centro Cultural El Barro et al., 2013). Como ejemplo de esto, se señalaron las palabras de la entonces ministra de Educación provincial, Cristina Díaz, quien sostenía que "no se aplicará la ESI en las escuelas, porque no va con la idiosincrasia de la provincia" (Centro Cultural El Barro et al., 2013).

No obstante, esta interpretación de las activistas se sostiene por momentos y en otros no. Así, se señala una idiosincrasia sanjuanina conservadora como parte de una operatoria del poder político gubernamental, pero, en otras ocasiones, se atribuye a la propia sociedad ser actuante de una moral conservadora. Esto llevó a las activistas a posicionarse tanto frente a su propia sociedad como contra las decisiones políticas gubernamentales, al referenciarse como "quienes no formamos parte de esa idiosincrasia" (Centro Cultural El Barro et al., 2013). Estas contradicciones dieron lugar a discusiones sostenidas por las militantes en los años posteriores. El debate giraba en torno a las siguientes cuestiones: ¿es San Juan una sociedad conservadora o es la representación hegemónica que promueven las dirigencias políticas y eclesiásticas?, ¿todas las personas habitantes de San Juan se identifican en sus pensamientos y acciones con ese discurso hegemónico?, 
¿las militantes y activistas podemos considerarnos fuera de las operaciones del poder discursivo y hegemónico?

Respecto del aborto, este folleto enunció algunos posicionamientos y sentidos que analizaremos a continuación. En primer lugar, señalaba al Código Penal como el marco que establece el derecho a abortar en circunstancias específicas de riesgo para la salud, la vida o en caso de embarazo producido tras una violación. A la vez, denunciaba que "hace casi un siglo no podemos interrumpir un embarazo fruto de una violación o cuando de continuarlo nuestra vida y nuestra salud corren riesgos, situaciones legalmente no punibles" (Centro Cultural El Barro et al., 2013).

Por lo anterior, entendemos que hablar de derechos y legalidad con relación a las circunstancias que habilitan el aborto era una apuesta política que comenzaba a distinguirse de aquéllas que hablaban de permisos o exclusivamente de no punibilidad. Es probable que estas distinciones no hayan estado del todo sopesadas en ese momento, pero, de algún modo, consideramos que fue un comienzo para transitar hacia posicionamientos más arriesgados. Otro aspecto importante que apuntar es que el texto señalaba como sujeto del aborto exclusivamente a mujeres y niñas, asunto que fue problematizado posteriormente por los feminismos.

Ahora bien, aunque el folleto reconocía que, en ese momento, año 2013, "son varias las provincias en nuestro país que han implementado en los hospitales públicos el protocolo para la atención de abortos no punibles", también denunciaba al estado provincial por negarse a tomar estas medidas "incurriendo en una violación a las obligaciones del Estado argentino y obligando a miles de mujeres y niñas a practicarse un aborto riesgoso" (Centro Cultural El Barro et al., 2013). Sobre las dificultades en el acceso a abortos, también se posicionaba en contra de aquellxs "profesionales de la salud [que] han eludido su responsabilidad médica, amparándose en la objeción de conciencia como excusa" para negar el acceso a abortos legales (Centro Cultural El Barro et al., 2013).

El texto reconocía las prácticas históricas de las mujeres para controlar su reproducción: "Las mujeres podemos decidir sobre nuestras vidas, si tener hij@s, cuándo y cuántos. Desde tiempos remotos, decidimos si continuar con un embarazo o no, aunque los estados y la sociedad no reconozcan nuestra soberanía sobre este primer territorio que es nuestro cuerpo" (Centro Cultural El Barro et al., 2013). Sin embargo, también denunciaba la ilegalidad del aborto como un problema que afecta desigualmente a las 
mujeres, de acuerdo con sus posibilidades o no de pagar abortos seguros en clínicas privadas. En condiciones desiguales, quienes "ponen en riesgo la vida [son] las mujeres empobrecidas que no pueden pagar una clínica privada y que deben recurrir a métodos inseguros e insalubres, es decir que la penalización del aborto no disminuye su práctica" (Centro Cultural El Barro et al., 2013).

Entendemos que, en el folleto, la clandestinidad se concibe como contracara de la legalidad; es indicada como un ámbito en donde la única experiencia posible -o mayormente posible- está signada por el riesgo, la inseguridad, la insalubridad. Este punto fue discutido reiteradas veces en los años siguientes, principalmente desde la conformación, en 2014, de la organización Las Hilarias Socorristas en Red en la provincia. Con la presencia de grupos que se organizan para acompañar y cuidar a quienes abortan en contextos restrictivos de legalidad, las representaciones sobre la clandestinidad y la legalidad se han complejizando. A partir de estas perspectivas, no se opone legalidad con inseguridad, sino que se reconocen formas violentas dentro de lo legal y formas seguras por fuera de lo institucional. Es decir que las experiencias que tienen lugar en el ámbito de lo legal e institucional no necesariamente son seguras: pueden ser violentas e inseguras; así mismo, aquéllas que ocurren en la clandestinidad no necesariamente son riesgosas, sino que pueden ser cuidadas y respetuosas (Iturrieta, 2019; Pessio, 2020; Iturrieta, 2021a).

Por último, el texto finaliza el apartado sobre aborto con una frase que no reproduce la consigna tripartita de la Campaña Nacional, sino que declara que "El aborto legal, seguro y gratuito es salud, dignidad y justicia social" (Centro Cultural El Barro et al., 2013).

En noviembre, la potencia viajera de los encuentros, como llamamos a este tráfico de ideas, afectos y cuerpos, llegó a San Juan y sumó nuevas protagonistas. Había una generación que participaba por primera vez en una movilización de tal magnitud. Las corporalidades, los carteles, el modo de habitar los espacios públicos - como bañarse en las fuentes de agua de las plazas - conformaron una estética política nunca vista en las calles de nuestra cotidianidad.

Luego del ENM, se constituyeron colectivas y grupos feministas que confirmaron lo que muchas sabían: que quien participa en un encuentro no vuelve igual. Surgieron La Joroba Colectiva Feminista, el Frente Feminista Las Martinas, Las Hilarias Socorristas en Red y muchas agrupaciones li- 
gadas a partidos políticos. La masividad del encuentro, la participación de activistas en la organización de éste, las marchas realizadas fueron semillero de militancias feministas y activistas juveniles. Los años siguientes no serían igual.

Un punto que hay que destacar es que la fecha del ENM fue la resultante de una puja política, en la que el gobierno de la provincia consiguió impedir que el evento se desarrollara en plena campaña electoral. Así, la Comisión Organizadora del encuentro cedió su realización en su fecha original, alrededor del 12 de octubre, día de lucha contra la colonialidad y por la diversidad cultural.

Posteriormente, hacia el 8 de marzo de 2014, se difundió un panfleto firmado por el Centro Cultural El Barro y la Campaña por el Derecho al Aborto San Juan (Centro Cultural El Barro et al., 2014). Varias activistas, entre ellas integrantes del Barro, buscábamos abrir y dar fuerza a un espacio como la Campaña Nacional en la provincia. Las acciones no estaban coordinadas con la campaña a nivel nacional, ni siquiera teníamos participación en sus espacios de articulación. Sin embargo, consideramos que dar cuenta de un espacio de lucha por el aborto en San Juan nos serviría para instalar el tema ante los esfuerzos de los sectores dirigentes por negarlo.

El panfleto comenzaba con un llamado a pensar críticamente nuestra posición y sujeción corpoafectiva y sexual en el marco de relaciones sociohistóricas concretas:

¿De quién son nuestros cuerpos? El de cada una. ¿Son de nuestros padres, madres, maridos o hij@s? ¿Quién lo cuida, quién lo viste, quién lo alimenta y lo lleva puesto toda la vida? ¿Quién lo siente? ¿Es que acaso toda la sociedad tiene poder de decisión sobre nuestros cuerpos y nuestras vidas? ¿Aquellas personas, instituciones sociales o religiosas pueden tomar decisiones en nuestro nombre? En ese Estado que somos tod@s, ¿̇en dónde estoy YO, en dónde mis derechos? (Centro Cultural El Barro et al., 2014)

El cuerpo, la vida propia que cada quien lleva adelante, frente a la autonomía negada. "Vivimos vidas sujetas a decisiones ajenas" era la idea puesta en el centro de la escena.

Nuevamente, el sujeto del aborto eran las mujeres. Así, el problema de la criminalización del aborto se relacionaba con la maternidad como 
imposición. Frente a esto, se reivindicaba a quienes cada vez más "optamos por no ser madres, o por una maternidad voluntaria y planificada. Creemos que el hecho de tener cuerpos capaces de gestar y parir no nos obliga a desear hacerlo, y asumimos esta decisión sin culpas ni penas" (Centro Cultural El Barro et al., 2014).

Se repetía la denuncia al estado provincial por incumplir las normas judiciales y procedimentales con relación a los abortos no punibles, a la vez que se señalaba el abandono del Estado respecto de legalizar el aborto. Ante tal desidia, el llamado era a las mujeres "de todas las edades y colores, porque necesitamos caminar juntas y retomar los senderos que nos pondrán cada vez más en pie de igualdad de condiciones con nuestra sociedad" (Centro Cultural El Barro et al., 2014).

Por último, el boletín convocaba al "Estado y a la sociedad sanjuanina a abrir el debate sobre el Proyecto de Ley de Interrupción Voluntaria del Embarazo" (Centro Cultural El Barro et al., 2014). Si bien se mencionaron las consignas tripartitas de la Campaña Nacional, el boletín cerró con una elaboración propia que ya se había incluido en producciones anteriores: "El aborto legal, seguro y gratuito es salud, dignidad y justicia social" (Centro Cultural El Barro et al., 2014).

En junio de 2014, como anticipamos, se constituyó Las Hilarias Socorristas en Red. Esta agrupación integró la organización nacional Socorristas en Red que, hasta la actualidad, produce y difunde información sobre aborto, y acompaña a quienes deciden abortar. ${ }^{16} \mathrm{El}$ surgimiento de una colectiva socorrista en San Juan constituyó un hito, ya que permitió penetrar en sectores institucionales para producir conocimiento sobre experiencias de personas que abortan. Al proponerse no sólo el acompañamiento de personas que abortan sino el registro de dichos acompañamientos, permitió contar con datos fehacientes sobre abortos en San Juan, atendiendo a aspectos escasamente indagados hasta el momento por los estudios sobre aborto. Así, a partir de un trabajo de sistematización, las socorristas elaboraron información sobre aspectos socioeconómicos, laborales, educativos, antecedentes ginecológicos y obstétricos, situaciones de violencia,

16 Algunos estudios locales sobre Las Hilarias y experiencias de aborto con acompañamiento socorrista fueron realizados por Paloma Chousal Lizama y Florencia Rodríguez (2017), así como por Yanina Iturrieta $(2019 ; 2021 a)$. 
prácticas de cuidado sexual de las personas que se comunicaba con ellas para solicitar ayuda para abortar. Además, generaron conocimientos sobre procedimientos de aborto con medicamentos y sobre cómo es la atención de situaciones de aborto en el sistema de salud en aquellos casos en los que se haya sido utilizado este servicio.

Las acciones de Las Hilarias giraron, en principio, en torno a la realización de talleres abiertos sobre el uso seguro de misoprostol y las presentaciones de datos de abortos en San Juan, además de los acompañamientos a personas que necesitaban abortar. Hubo progresividad en la visibilidad de las socorristas en el espacio público: lo que en principio se daba en la universidad, en aulas más pequeñas, luego se trasladó a espacios más amplios, públicos, con mayor difusión y concurrencia.

Ese año también se constituyó La Joroba Colectiva Feminista, una organización política, apartidaria, que proponía, en palabras de unx de sus integrantes, "trabajar toda la violencia que se desprende desde el patriarcado, sin banderas" (Muñoz, Martin y Panis, Comunicación personal, 2014). En una entrevista realizada a sus activistas, manifestaron que La Joroba surgió cuando

una chica larga un evento invitando a hablar sobre lo que había pasado en San Juan y por toda la violencia que se había generado en torno al Encuentro. Eso se viralizó y a esa reunión caímos un montón de personas y ahí decidimos armar La Joroba. (Muñoz, Martin y Panis, Comunicación personal, 2014)

El nombre La Joroba hace alusión al lugar de encuentro de estxs activistas: una plaza céntrica de San Juan con una elevación de terreno parquizada que les permite sostener un espacio abierto a la participación de quien se acerque. Una característica de esta colectiva feminista es que está conformada por personas asignadas como varones y como mujeres.

Entre sus acciones, realizaron un taller abierto el 7 de marzo, día de lucha contra la homo-lesbo-trans-bifobia, al que invitaron a compañeras trans. Esto les permitió replantearse la "pronunciación colectiva de género y, justamente, cuál es la situación de las compañeras trans" (Muñoz, Martin y Panis, Comunicación personal, 2014). Luego de algunos debates, comenzaron a posicionarse desde el feminismo. 
Otro de los debates que encararon tuvo que ver con las infancias: "cómo construimos las infancias, cómo están los estereotipos de género fuertemente marcados en las infancias" (Muñoz, Martin y Panis, Comunicación personal, 2014). Según lxs militantxs:

la idea del patriarcado [...] está agarrada a muchas ideas: la homofobia, el capitalismo, la violencia. Lo hemos charlado mucho y ha sido mucha la construcción identitaria de La Joroba para ir justamente repensando. Por eso nos pensamos feministas, o sea, pensar en cómo el patriarcado tiene sus diferentes matices, sus diferentes puntitos, para ir atacándonos, para ir moldeándonos. (Muñoz, Martin y Panis, Comunicación personal, 2014)

Sus integrantes caracterizaron a San Juan como "una provincia muy despolitizada", lo que dificulta "dar los debates desde posicionamientos feministas" (Muñoz, Martin y Panis, Comunicación personal, 2014). Plantearon que esta dificultad se agravaba mucho más en los departamentos alejados. Al respecto, relataron que habían viajado al departamento Jáchal, ubicado a $160 \mathrm{~km}$ de la capital, para dar un taller de educación sexual integral. La iniciativa surgió de las propias docentes de esa región, quienes les plantearon la necesidad de la ESI y el poco o nulo apoyo que recibían para poder abordar sus contenidos. También destacaron las dificultades de acceso a internet en localidades alejadas. El planteo territorial era importante para esta colectiva.

Ahora con La Joroba nos estamos planteando un trabajo mucho más profundo, que siempre se estuvo hablando, que es esto de la organización barrial, que es lo que queremos, ir a los barrios, que es lo que me parece más interesante para mí, para la militancia. (Muñoz, Martin y Panis, Comunicación personal, 2014)

Sin embargo, no sólo advertían dificultades para debatir ciertos temas en sectores de la sociedad sanjuanina -identificados desde sus discursos como ajenos a su organización-, sino que algunas integrantes de La Joroba reconocían tensiones para llegar a un consenso sobre el problema del aborto dentro de la colectiva. Después de discutirlo un tiempo, acordaron su adhesión a la Campaña Nacional (Muñoz, Martin y Panis, Comunicación personal, 2014). 
Es decir que las dificultades y tensiones en ciertos debates existen en la sociedad y en las organizaciones que la constituyen. Ante esto, volvemos a preguntarnos: ¿por qué lxs activistas no siempre pueden reconocerse como parte de la sociedad que habitan? Lo que, a su vez, les impide reconocer que los problemas que critican en la sociedad también se relacionan, al menos en parte, con los problemas de los espacios que integran.

Otra de las organizaciones surgidas tras el ENM que sumó su participación a la Campaña Nacional fue el Frente Feminista Las Martinas. La Joroba y esta colectiva mantuvieron una fuerte articulación durante los años que estuvieron activas en San Juan. Tras su disolución, sus integrantes pasaron a formar parte de otros espacios profesionales y de activismo o migraron a otras provincias. Lo cierto es que, en su mayoría, continúan activando en pos de los derechos de género, diversidades y disidencias sexuales.

En 2015, la movilización convocada de forma espontánea bajo la consigna "Ni una menos" representó un grito masivo de rabia, furia, dolor que, a través de manifestaciones públicas, se hizo sentir en San Juan, el país y parte de Nuestramérica. Las asambleas previas convocaron a numerosas organizaciones y personas no agrupadas. Incluso el gobierno provincial organizó reuniones a una semana de la marcha con la intención de dialogar con distintos grupos. Éste fue uno de los puntos de tensión en el activismo local, ya que, finalmente, y sin mediar aclaraciones, ese día el Gobierno colocó un escenario en medio del recorrido de la marcha. La tensión entre estos espacios tuvo una fuerte interpelación visual entre quienes participamos en la manifestación.

Esta tensión entre Estado y feminismos se encuentra presente en cada momento analizado. En una provincia en donde, como hemos mostrado, la política de género es contraria a los derechos de mujeres y diversidades sexuales, las vinculaciones son posibles en torno a demandas muy puntuales y sólo con agentes estatales afines a los movimientos, como ciertas funcionarias militantes o trabajadoras estatales.

Otra tensión se produjo a raíz de que el Movimiento de Mujeres Sanjuaninas, organización de mujeres con trayectoria en San Juan, rompió -el mismo día de la marcha y en movilizaciones posteriores- con la convocatoria general organizada bajo la bandera del "Ni una menos". Uno de los aspectos con los que en ese momento no estuvieron de acuerdo fue la consigna a favor de la legalización del aborto, aunque tampoco se opusieron públicamente. 
En 2016 se convocó en todo el país a la Campaña por la Libertad de "Belén", ${ }^{17}$ joven presa por un aborto involuntario en la provincia de Tucumán. El 12 de agosto, nos congregamos en San Juan y en todo el país para realizar bocinazos, intervenciones de espacios públicos y movilizaciones por la libertad de Belén, quien gracias a la lucha de los movimientos feministas fue absuelta.

Ese mismo año, el 19 de octubre, realizamos el 1. ${ }^{\text {er }}$ Paro Nacional de Mujeres. Éste marcó una diferencia en el carácter de la protesta, ya que surgió luego del aumento en la cantidad y la crueldad en los femicidios y ante la ausencia de políticas por parte del Estado. Este primer paro se convocó en respuesta al cruel femicidio de Lucía, lo que le dio un carácter diferente a las luchas contra las violencias machistas; el lema fue "Nosotras paramos. Vivas nos queremos".

El 8 de marzo de 2017, se convocó a un Paro Internacional Feminista para aunar las demandas contra las violencias machistas y el patriarcado desde la interseccionalidad de las opresiones. "Si nuestras vidas no valen, produzcan sin nosotras", fue la consigna utilizada.

Ese 8 de marzo, ${ }^{18}$ que fue nombrado como $8 \mathrm{M}$ (Iglesias, 2020), constituido a nivel internacional como Día de las Mujeres Trabajadoras, se colmó de sentidos. Así, el paro, instrumento de la lucha de clases, se ligó al trabajo no pago de las mujeres, el trabajo invisibilizado, el trabajo reproductivo, la precarización de las mujeres y disidencias, las tareas de cuidado, el hecho de que sean las mujeres las que sostienen la vida en los territorios y, más aún en momentos de ajustes, la precarización de la vida y la recolonización.

Las madres jachalleras que luchan por el agua y en contra de la megaminería en una región explotada por empresas multinacionales (Rodríguez, Ruarte, 2019), las madres de víctimas de femicidio, las mujeres que sostienen comedores populares, las feministas que acompañamos en situaciones de violencia y en situaciones de desobediencia a los mandatos. Los paros internacionales de mujeres van sumando distintos territorios, sumando

17 Belén es el nombre ficticio con el que se conoce a la joven tucumana que estuvo presa durante dos años por un aborto espontáneo.

18 El 8 de marzo se conmemora la muerte de 129 mujeres en la fábrica Cotton (Chicago) en 1908 durante una huelga iniciada para exigir una jornada laboral de ocho horas, una remuneración igual a las de sus compañeros varones y condiciones dignas de trabajo. Ocupaban la fábrica en protesta cuando ésta ardió. 
países y motivos a la huelga. Constituyen un hito más en las disputas de los feminismos como sujetos políticos de transformación emancipadora.

El documento leído por Ni unx Menos en la concentración del 8M, elaborado a nivel nacional por esta articulación e intervenido por lxs miltantes sanjuaninxs, ${ }^{19}$ se manifiesta con fuerza por el aborto legal; el tercer punto del documento expresa lo siguiente:

\section{PARAMOS PORQUE QUEREMOS DECIDIR SOBRE NUESTROS CUERPOS. EXIGIMOS ABORTO LEGAL, SEGURO Y GRATUITO. \#ABORTO LEGAL, SEGURO Y GRATUITO.}

- Paramos para que el Congreso Nacional apruebe el proyecto de Ley de Interrupción Voluntaria del Embarazo, presentado en 2016 por sexta vez.

- Porque el aborto clandestino inseguro es la principal causa de muerte de mujeres gestantes. Porque es vulnerando un derecho humano básico que el aborto ilegal es femicidio en manos del Estado, y una deuda de nuestra democracia.

- Defendemos el acceso a la interrupción legal del embarazo sea por la causal que sea. Exigimos el acceso a los abortos no punibles en cumplimiento del fallo F., A. L sancionado en 2012 por la Corte Suprema de la Nación. Gritamos: Justicia por Juana, niña perteneciente a una comunidad wichi de la provincia de Salta, abusada por 7 hombres y violentada luego por un Estado que la privó de su derecho a acceder a un aborto no punible.

- En este paro internacional de mujeres que nos hermana, denunciamos pública e internacionalmente a El Salvador, Honduras, Nicaragua, República Dominicana, Haití y Surinam como ESTADOS FEMICIDAS; ya que, al ser los únicos 6 países en América Latina con prohibición absoluta del aborto, son responsables de las muertes y

19 Esta declaración fue leída al finalizar el recorrido de la marcha del 8M en San Juan. El texto base fue elaborado por la coordinación Ni Unx Menos a nivel nacional (puede leerse en Página 12, 2017); lxs militantes sanjuaninxs lo intervinieron y agregaron fragmentos consensuados a nivel local. Así, en el apartado citado, el último ítem es una intervención de lxs sanjuaninxs. 
graves violaciones al derecho a la salud de cientos de niñas y mujeres en sus territorios.

- Exigimos \#AbsoluciónParaBelén, criminalizada por asistir a un hospital público tucumano con un aborto espontáneo en curso. ¡Ninguna mujer presa ni muerta por abortar! ¡Basta de criminalizar nuestros cuerpos y decisiones! ¡Vivas y Libres Nos Queremos!

- "Educación sexual para decidir, anticonceptivos para no abortar, aborto legal para no morir. Aborto legal porque en mi cuerpo decido yo".

- Paramos contra toda práctica, contra toda ley criminalizadora sobre nuestro derecho a decidir ¡nuestros cuerpos, son nuestro territorio soberano. Seguimos armando redes de cuidados y acompañamientos, construyendo saberes colectivos. (Ni Unx Menos San Juan, 2017)

En 2017, con un fuerte consenso dentro de la Campaña Nacional, se decidió acompañar la presentación por séptima vez en el Congreso del proyecto de aborto legal. La presentación se acompañó por una convocatoria de pañuelazos verdes en todo el país. El debate en torno a este proyecto fue el inicio del siguiente momento, que consideramos uno de los puntos más álgidos en nuestra historia feminista colectiva.

\section{Tercer momento: Ia marea verde en San Juan}

En 2018 se presentó por séptima vez en el Congreso el Proyecto de Ley de Interrupción Voluntaria del Embarazo de la mano de la Campaña Nacional por el Derecho al Aborto Legal, Seguro y Gratuito. Esto motivó diversas acciones en todo el país y, sobre todo, una fuerte presencia política en el espacio público.

El 19 de febrero de 2018, se realizó el primer pañuelazo, un evento que recorrió las ciudades de todo el país. Éste consiste en manifestaciones públicas en las que se muestra el pañuelo verde, distintivo de la Campaña Nacional, que lleva impresa la consigna "Educación sexual para decidir, anticonceptivos para no abortar, aborto legal para no morir".

En San Juan, diversas agrupaciones feministas empezaron a convocar a pañuelazos multitudinarios en plazas centrales de la provincia, en hospitales centrales, en la universidad pública, entre otros espacios. Los pañuelazos se impusieron como fuertes acciones de visibilización; la presencia del símbolo de los pañuelos verdes apareció cada vez con más insistencia. En la escena de estas manifestaciones, destaca la participación de jóvenes 
niñas y adolescentes con sus uniformes escolares, a veces acompañadas de sus madres o tías, muchas veces en grupos, develando la fuerte impronta intergeneracional de la marea verde.

Este fuerte activismo verde se impuso en la agenda mediática hegemónica. El debate se instaló en la agenda pública, así como en el ámbito privado de las reuniones familiares, laborales y de amistades. El tratamiento de la propuesta en la Cámara de Diputados se tornó inminente.

Los cabildeos de la Campaña Nacional fueron una de las principales acciones concertadas a nivel central y en Buenos Aires para convocar a representantes de diversos partidos a que se expresaran a favor del proyecto de ley. Sin embargo, en la provincia, esta acción no fue acordada. La dirigencia política cerró sus filas a los feminismos; pese a algunos intentos de lograr una audiencia con ciertos sectores peronistas, éstos rechazaron toda posibilidad.

Empezaron a establecerse contactos e intercambios entre activismos de Buenos Aires, activismos regionales y de las provincias, en pos de coordinar acciones de incidencia político-social a favor del aborto legal. Se consolidaron reuniones entre trabajadores y profesionales de diversos ámbitos con grupos feministas para coordinar debates y diferentes acciones.

Se conformó en San Juan la Red de Profesionales de la Salud por el Derecho a Decidir, el Grupo de Juristas - abogadxs a favor del derecho a decidir; hoy Juristas por la Igualdad de Género y los Derechos Humanos-y diversas redes de comunicadorxs y periodistas a favor del aborto legal con articulaciones a nivel nacional y regional. Se coordinaron acciones masivas para visibilizar la marea verde en San Juan; una de éstas fue el FestiVerde, una jornada artística-política organizada por diversos grupos feministas y activistas a favor de la ley.

Al mismo tiempo, surgieron reacciones de los sectores más conservadores, como la organización Ola Celeste de San Juan, que realizaron fuertes ataques por redes sociales y acciones de disciplina en las instituciones; por ejemplo, hubo sanciones para personas (docentes, estudiantes) que llevaran el pañuelo verde, pero no para quienes portaran el pañuelo celeste (distintivo de personas que se oponen al aborto). Una de las jóvenes sancionadas por llevar el pañuelo verde menciona lo siguiente:

Me suspendió mi vicedirectora diciéndome que básicamente yo le faltaba el respeto, que no puedo ir por la vida generando problemas [...]. También mi preceptor me sugirió que quemara mi pañuelo. Y bueno, 
falté los dos días que me correspondían. Y ese día que me suspenden, me dicen: "acá no se usa ninguna insignia, ni a favor de la vida ni en contra, ni celeste, ni verde, ni nada". Y bueno, resulta que cuando vuelvo el viernes me enteré que los profesores andaban con pañuelos celestes, que los alumnos andaban con pañuelos celestes. Y yo misma vi al entrar al colegio, vi toda la puerta empapelada de afiches de sí a la vida. (Comunicación personal, citada en Iturrieta, 2018)

Durante este periodo y en el momento posterior al tratamiento de la ley, se sucedieron diversas situaciones de hostigamiento y agresión, tanto en redes sociales como en espacios públicos, hacia quienes estos sectores identificaban a favor del aborto legal.

Ni Unx Menos San Juan publicó documentos en los que afirmaba "Somos más fuertes que el odio" (Chousal Lizama, 2020) frente a las diversas agresiones y hostigamientos que recibían activistas en nuestra provincia en diversos ámbitos como los laborales, profesionales, educativos, sociales. También se reforzó la presencia de "las pibas/pibis", grupos de adolescentes y jóvenes que llevaron los debates por la ampliación de derechos a toda escuela e institución; lxs más jóvenes como sujetos políticos. Con ellxs, las movilizaciones y pañuelazos se colmaron de glitter, pinturas e intervenciones en los cuerpos, junto a las más diversas expresiones artísticas y performances.

Los intercambios y redes se fortalecieron para generar las más diversas estrategias de incidencia social y política. La coordinación de acciones comunicacionales buscó el tono que evidenciara las ausencias de derechos.

Ante los discursos de algunos sectores que justificaban el silencio sobre la existencia de los abortos con base en una homogeneización de la sociedad que caracterizaban como no preparada para participar en esos debates, las pibas cambiaron el mapa político con su presencia en las manifestaciones. Ese año, los debates sobre la criminalización de la práctica fueron parte de las mesas familiares, las calles y las escuelas; se hizo más visible que nunca la potencia política de los feminismos respecto de los ámbitos personales (Chousal Lizama, 2021). La tensión entre sentidos y símbolos permaneció en el ámbito público más allá de las movilizaciones militantes: el pañuelo verde y el celeste, la palabra vida y muerte, los derechos de mujeres y personas gestantes frente al "no nacido". 
En este contexto, fue posible una mayor visibilización de situaciones de niñas forzadas a parir, de obstaculizaciones en el acceso a los abortos no punibles, de la violencia institucional, sanitaria, judicial, mediática contra quienes solicitaron un aborto. Todas estas faltas, más el conocimiento del escandaloso número de niñas forzadas a parir en nuestra región y los datos aportados por Socorristas en Red, dieron lugar a la profundización y masividad de los debates.

Ante el aumento de casos de niñas que acudieron a las socorristas a nivel nacional, se planteó la campaña En un Mundo Justo, las Niñas No son Madres. ${ }^{20}$ Desarrollada en todas las ciudades del país con presencia socorrista, la campaña visibilizaba el problema de los embarazos en infancias y adolescencias, y la violencia que implica obligar a llevar a término esos embarazos al negar opciones de aborto.

La campaña estuvo compuesta por murales, afiches, spots radiales que interpelaban sobre los derechos de las infancias y adolescencias: "las queremos vivas de risa, vivas jugando". Una integrante de Hilarias afirma que fue "una campaña realizada con mucho amor y mucho cuidado"; añade que el objetivo es visibilizar que, en nuestro país, cada tres horas, una niña es obligada a gestar, parir y criar según estadísticas oficiales nacionales (Integrante de Las Hilarias, en Radio La Lechuza, 2020).

Por ello y ante el día de las infancias en Argentina, planteamos visibilizar esta situación para garantizar los derechos de las niñas y adolescentes a vivir libres y felices, a jugar, no a pasar por situaciones de torturas. Son niñas y tienen derecho a vivir las infancias. (Integrante de Las Hilarias, en Radio La Lechuza, 2020)

Por esto, llamaron al Estado, a los gobiernos y a todos y todas a involucrarse en el cuidado de las infancias. Las activistas hicieron énfasis en las responsabilidades del Estado por la no aplicación de la ESI ni del protocolo de interrupción legal del embarazo. En San Juan, Las Hilarias convocaron a otras colectivas a realizar un mural colaborativo sobre la temática en la

20 Datos revelados por Unicef exponen la vulneración de derechos de las niñas y la necesidad de cuidar las infancias. Las niñas que cursan embarazos forzados sufren dilaciones del Estado, exposiciones mediáticas y riesgos obstétricos cuando deberían tener derecho a estar jugando y riendo (véase Socorristas en Red [feministas que abortamos], 2021). 
Biblioteca Popular Alfonsina Storni; este evento se acompañó con ferias y charlas (Integrante de Las Hilarias, en Radio La Lechuza, 2020).

En abril de 2018, el Equipo de Investigación en Género y Ciudadanía (FACSO-UNSJ) organizó un Conversatorio sobre el Derecho a Decidir, al que acudieron activistas de distintas organizaciones, así como docentes y estudiantes (Equipo de Investigación en Género y Ciudadanía, 2018). El evento se realizó en el marco del debate en el Congreso de la ley IVE. Se eligió la opción de un conversatorio y no la de un panel, ya que la idea era recoger experiencias y posicionamientos. Allí se dieron debates sobre los sentidos que ligamos al aborto - como la muerte, la pobreza o el traumapara problematizarlos y hacer audibles otros sentidos también existentes pero negados por los discursos hegemónicos.

"Queremos aborto y queremos un aborto feminista, afectuoso, acompañado. Y queremos poder elegir dónde y con quién abortar, disputando poder a la medicina sobre nuestros cuerpos", declararon estudiantes participantes y, entre ellas, militantes socorristas (Equipo de Investigación en Género y Ciudadanía, 2018). Esta disputa de sentidos también se daba, sobre todo, en las marchas, a través de los cantos, en los documentos, en los símbolos y performances artísticos. Pero los espacios de debates e intercambios fueron relevantes para elaborar argumentos y posiciones que permitieran profundizar las reflexiones.

Así, en uno de los cánticos más populares de las marchas, algunas feministas dicen "Aborto legal en el hospital" y otros sectores feministas cantan "Aborto legal en cualquier lugar". Las primeras circunscriben la legalidad al ámbito de la institucionalidad sanitaria, en donde lxs profesionales médicos arbitran el procedimiento de aborto, lo que garantizaría su seguridad. Esta postura equipara legalidad con seguridad e institucionalidad médica y otorga todo el poder al Estado.

El otro sector del feminismo propone ampliar las opciones y que sea quien va a abortar quien decida dónde hacerlo. Entienden que las personas son capaces de decidir y realizar un procedimiento abortivo de modo ambulatorio (en un ámbito no hospitalario como es la casa propia) de forma cuidada, siempre y cuando dispongan de recursos e información adecuada, la cual sí debe estar garantizada por el Estado. Desde esta posición, la legalidad no debería limitarse a garantizar abortos sólo en el ámbito sanitario, que por sí mismo no garantiza seguridad y trato respetuoso. En este sentido, problematizan las prácticas sanitarias al denunciar el maltrato y la 
obstrucción que algunos efectores de salud imponen a quienes solicitan un aborto. Además, reivindican la capacidad organizativa de las personas gestantes y las feministas para dar solución a sus problemáticas en diferentes contextos, poniendo de relieve esa potencia.

Poder decidir cómo abortar, dónde hacerlo, acompañada de quiénes son aspectos que se debaten al interior de los feminismos locales. En síntesis, se disputan los alcances de la pretendida legalidad en torno al aborto o, más bien, los alcances del derecho que se considera justo conquistar. Se trata de tensiones no resueltas que conllevan diferentes posicionamientos relacionados con la autonomía, el poder médico, los límites de la legitimidad del aborto, los sentidos que pone en juego.

Sin duda, la posibilidad de contar con un cúmulo de experiencias y saberes en torno al aborto con medicación, desarrollado principalmente gracias a las experiencias de quienes abortaron, permitió poner en el centro del debate el poder de quien decide interrumpir un embarazo para, junto a otrxs, con cuidados, llevar adelante el proceso de forma segura aún en contextos de clandestinidad. Las socorristas fueron parte de ese proceso como acompañantes y productoras de saberes. Poner de relieve tales experiencias, respaldadas por evidencia de los saberes colectivos, sentó una posición ineludible en este debate.

\section{El saldo de 2018: a la clandestinidad no volvemos nunca más}

Si bien en junio la Cámara de Diputados de Argentina aprobó el proyecto de ley, en agosto, ante el tratamiento en el Senado, la ley no obtuvo la cantidad suficiente de votos a favor para su aprobación final. Sin embargo, el saldo de este proceso excede ampliamente la disputa legislativa (Córdoba y Domínguez, 2019).

A finales de 2018, se conformó la Red de Comunicadorxs con Perspectiva de Género de San Juan (RECOPE) ${ }^{21}$ con la idea de generar acciones de incidencia dentro de los medios locales y con relación a redes de comunicadorxs y periodistas de otras regiones y provincias (Chousal Lizama, 2020). A partir de la información contenida en las redes sociales de RECOPE, podemos dar cuenta de que una de sus primeras acciones de visibilización fue

21 Colectiva de comunicadorxs de San Juan interesada en debatir desde la perspectiva de género (véase Red de Comunicadorxs con Perspectiva de Género de San Juan, 2018). 
una muestra fotográfica de la marea verde local que denominaron "Ahora que sí nos ven". Se montó en la sala del Cine Teatro Municipal, ubicada frente a la plaza principal de San Juan. Por orden de las autoridades de la sala, la muestra tuvo que ser suspendida y levantada al día siguiente (M. Silva, Comunicación personal, 22 de diciembre de 2018).

Durante el 2019, se mantuvieron las redes y se afianzaron estrategias. Continuaron los pañuelazos, las intervenciones en espacios públicos -como colgar cintas verdes-, las marchas de la agenda feminista con la consigna "Aborto legal ya", las intervenciones con perejiles y perchas acompañadas de las consignas "A la clandestinidad no volvemos nunca más" y "Las perchas al ropero, el perejil a la cocina", así como los escraches con rostros de lxs senadores de San Juan que votaron en contra de la exigencia de más derechos.

Se mantuvo la masa crítica impulsada en los debates de 2018 y las diversas propuestas de acciones de articulación entre redes. Así, en junio de 2019, se realizaron las Jornadas de Incidencia sobre Derechos Sexuales Reproductivos y no Reproductivos, organizadas colectivamente entre las organizaciones feministas Las Hilarias Socorristas en Red San Juan, Red de Profesionales de la Salud por el Derecho a Decidir San Juan, Espacio de Sociología Feminista(s), Departamento de Sociología, Ni unx Menos San Juan, Red de Comunicadorxs con Perspectiva de Género y Equipo de Investigación Género y Sexualidades (2019). Las jornadas plantearon nuevos horizontes posibles de articulación entre grupos de trabajadorxs de la salud, la educación, la comunicación y juristas, entre otros.

Hacia finales de 2019, asumió la presidencia Alberto Fernández, quien entre sus ejes de campaña preelectoral se había posicionado a favor del aborto legal en Argentina. El clima favorable se vio interrumpido al poco tiempo de haber iniciado el nuevo mandato presidencial. A comienzos de 2020, se produjo la pandemia mundial de COVID-19; el periodo de aislamiento social preventivo y obligatorio (ASPO) irrumpió en el mundo e inmovilizó las diversas acciones y manifestaciones públicas feministas de la marea verde. Si bien se propusieron diversas acciones comunicacionales en redes sociales, la crisis a nivel planetario paralizó todo tipo de acciones que necesitaran encuentros, intercambios, movilización colectiva y en espacios públicos.

No obstante, este escenario

facilitó la conformación de los primeros equipos de ILE en San Juan [...]. El establecimiento de las ILEs como servicio esencial por parte del

Córdoba, D., Lucero, G., Iturrieta, Y. y Chousal, P. (2022). Memorias feministas de la lucha por el aborto en San Juan, Argentina. Iberoforum, Revista de Ciencias Sociales, Nueva Época, 2(1), 1-50, Artículos, e000211. https://doi.org/10.48102/if.2022.v2.n1.211

Licencia Pública Internacional - CC BY-NC-ND 4.0 
Ministerio de Salud de la Nación, sumado a las alianzas de las organizaciones feministas con trabajadoras estatales, permitieron avanzar en estrategias tendientes a ampliar el acceso a ILEs en lugares donde no se implementaba y afianzar los servicios ya existentes. (Iturrieta, 2021b, p. 9)

Dichas circunstancias fueron capitalizadas por las organizaciones locales Las Hilarias y la Red de Profesionales de la Salud de San Juan: "a partir de mediados de 2020 y hasta comienzos de 2021, en el marco de la pandemia de COVID, ambas organizaciones en conjunto pudieron configurar cierta apertura en los servicios de aborto en el marco de la ley" (Iturrieta, 2021b, p. 10). En cierto sentido, "el 2020 fue la antesala inesperada para la actual implementación de la IVE en San Juan" (Iturrieta, 2021b, p. 12).

En octubre de 2020, empezaron a circular diversos rumores sobre la presentación del proyecto de ley IVE por parte del Poder Ejecutivo de Argentina. En noviembre, tomó estado público la definición política presidencial de presentar formalmente el proyecto de ley IVE en la Cámara de Diputados. De forma inmediata y simultánea, las diversas redes activistas, feministas y de diversos espacios empezaron a coordinar acciones; primero, para conocer el proyecto de ley del Ejecutivo y analizarlo con relación al proyecto de la Campaña Nacional; luego, para definir acciones a favor del aborto legal.

Se afianzaron las articulaciones y coordinaciones regionales y entre diversas provincias y redes federales con más consistencia. Se destaca el surgimiento de redes y encuentros de periodistas y comunicadorxs con carácter federal, algunas interesadas en el intercambio de contenidos y otras en la articulación estratégica de lo comunicacional para incidir en la agenda pública. Este ejercicio de trabajo en redes, todavía en formación y tensión, intentó trascender, desandar y apostar a construcciones colectivas "otras", horizontales y respetuosas de las construcciones y particularidades territoriales.

A diferencia de lo ocurrido en 2018, podemos decir que estas estrategias comunicacionales propusieron otros tonos y enfoques. La disputa de sentidos adquirió discursos y encuadres renovados con el interés de llegar a espacios y públicos más amplios de nuestra sociedad sanjuanina. Así, se instalaron consignas como "Aborto legal es vida", "Aborto legal es derecho de salud pública", "Aborto legal en San Juan", acompañadas con imágenes 
de representación e identidad cultural local-territorial como las montañas, la aridez, las cactáceas, el verde seco de alta montaña. Producciones comunicacionales situadas que recuperaban testimonios locales de experiencias de abortos en clandestinidad, que evidenciaban diversos motivos y condiciones y, sobre todo, testimonios de personas que habían cambiado de posicionamiento entre 2018 y 2020 al pasar de estar en contra de la ley a estar a favor del aborto legal, tras reconocer las debilidades del sistema estatal, para que toda persona acceda a una atención de la salud sexual reproductiva y anticonceptiva.

En 2020, fuimos partícipes y promotoras, es decir, militamos en la articulación que permitió la conformación de la Mesa por el Aborto Legal en San Juan como espacio de coordinación local entre diversas organizaciones: Red de Profesionales de la Salud por el Derecho a Decidir, Juristas por la Igualdad y los Derechos Humanos, Hilarias Socorristas en Red, Ni Unx Menos San Juan, Mala Junta, APDH, entre otras. Se señalaron registros de marcos legales sin cumplimiento como la ESI, insuficiencia en el sistema público de salud respecto a la distribución de métodos anticonceptivos y la falta de políticas públicas específicas que garanticen derechos sexuales reproductivos y no reproductivos, sobre todo en contexto de pandemia y ASPO.

Poco a poco, desde noviembre, se empezó a manifestar el debate político desde diversos sectores a favor del proyecto de ley presentado por el ejecutivo nacional. Poco a poco, la marea verde nacional y local realizó intensas campañas de acciones públicas, de producciones audiovisuales, gráficas, radiales con sentidos coordinados desde las infinitas redes feministas consolidadas, que lograron fundirse en el abrazo sororo más grande de los últimos años, el 30 de diciembre de 2020, por la Ley N. ${ }^{\circ} 27.610$ de Acceso a la Interrupción Voluntaria del Embarazo.

\section{Reflexiones finales}

En estas páginas hemos ensayado una memoria colectiva, situada y parcial sobre un proceso que entendemos común a muchas otras, junto a nosotras: el proceso de luchas por el derecho a abortar. Iniciamos un recorrido por numerosos archivos y registros de organizaciones amigas, hermanas, aliadas, con las que hemos debatido, discutido y disentido, pero con las que hemos sabido construir pisos de acuerdo para conformar una agenda común por el aborto legal. Lo consideramos un punto de partida para pensar(nos), 
para rememorar lo que fue posible lograr y para comprender lo que necesitamos continuar transitando.

Sabemos que estos acuerdos están armados por numerosos desacuerdos, y también decidimos habitarlos. Creemos que explicitarlos, tratarlos con cuidado, pero de frente, y hacerlos dialogar en espacios comunes nos permitirá mantener viva esa marea verde que nos supo conmover en la conquista por nuestros derechos. Con este impulso, recogemos algunas reflexiones a modo de aprendizajes construidos al calor de estas luchas con las que abortan, las que acompañan, las que luchan, las que cantan, las que escriben, las que intervienen con sus performances y actuaciones.

Así, pensar el aborto como un derecho implicó, en nuestros debates, discutir el sujeto de ese derecho: en primer lugar, sólo las mujeres, luego también las niñas y adolescentes, hasta que reconocimos otras existencias trans, no binaries, que reivindicaban poder abortar.

El qué del derecho no sólo se discutió en tribunales y senados, también en nuestros cantos, consignas y documentos. Reconocer cualquier motivo o causal como válidos y legítimos para que quien necesite abortar pueda hacerlo del modo que prefiera. Habiendo abortado una o más veces antes. Habiendo usado algún método anticonceptivo o no.

También el cómo o los alcances del derecho. Abortar hasta las doce semanas o hasta las catorce o sin límites de tiempo. Abortar en instituciones clínicas o también poder hacerlo en el espacio cómodo que cada unx elija. Abortar con asistencia médica o poder prescindir de ella.

Abortar con alegría, con placer, sentir alivio, dar lugar a la calma posterior, reír, llorar, llamar al producto del embarazo "bebé", llamarlo "feto", nombrarlo, ignorarlo, atravesar el duelo. Acompañar esos procesos, escucharlos, hacer audibles experiencias que no pensamos posibles. Pensar qué experiencias aún no hacemos audibles.

Con este trabajo nos planteamos asumir los nuevos desafíos que aparecen hoy en nuestras luchas feministas con una ley IVE en vigencia, pero con las más diversas obstaculizaciones y uno de los mayores patrimonios de lucha: reconocer la potencia feminista colectiva y horizontal que nos posiciona como sujetas políticas de la transformación social que deseamos. Nos convocamos aquí para compartir este primer paso de construcción de memorias feministas de Cuyo-San Juan, con la adrenalina que sólo la marea verde puede empujar desde nuestra matriz colectiva y con la 
responsabilidad de la herencia feminista que todxs y cada unx de nuestrxs compañerxs nos supo legar.

¿Para qué? Para dimensionar todo el trabajo y el aprendizaje de la lucha feminista verde y cuyana, pero, sobre todo, para plantear direccionalidad porque ninguna ley marca el fin de una demanda sino el inicio de nuevas y otras demandas que aún nos faltan. Para sentar presencia de un pasado reciente imprescindible para atravesar nuevos desafíos, un pasado reciente que, lejos de las añoranzas, se planta hoy para generar otras apropiaciones y nuevas luchas posibles.

\section{Referencias bibliográficas}

Agencia FARCO (2016). Homenaje a Lucy Collado: "Fue una mujer que nos cambió la vida en el instante de conocerla". http://agencia.farco.org. ar/noticias/10287/

Alma, A. y Lorenzo, P. (2008). Mujeres que se encuentran. Una recuperación histórica de los Encuentros Nacionales de Mujeres en Argentina (19862005). Feminaria.

Ávila, L. (2018). Géneros y ciudadanía sanjuanina. En L. Ávila y S. Kirby (comp.), ¿Ciudadanía para quienes? De los pactos sexuales al activismo de las mujeres y la diversidad en San Juan. Editorial Universidad Nacional de San Juan.

Barrancos, D. (2014). Participación política y luchas por el sufragio femenino en Argentina (1900-1947). Cuadernos de Intercambio sobre Centroamérica y El Caribe, 11(1), 15-26. https://ri.conicet.gov.ar/ handle/11336/3685

Brown, J. (2011). Derechos (no) reproductivos y sexuales en los bordes entre lo público y lo privado. Algunos nudos del debate en torno a la democratización de la sexualidad. En M. Petracci, J. L. Brown y C. Straw (eds.), Derechos sexuales y reproductivos: Teoría, política y espacio público (pp. 19-44). Editorial Teseo.

Campaña Nacional por el Derecho al Aborto Legal Seguro y Gratuito (s. f.). http://www.abortolegal.com.ar/

Carbajal, M. (2006a, 13 de noviembre). San Juan, una provincia Opus Dei. Página 12. https://www.pagina12.com.ar/diario/elpais/1-76116-200611-13.html

Carbajal, M. (2006b, 14 de noviembre). Los dispositivos ocultos. Página 12. https://www.pagina12.com.ar/diario/sociedad/3-76153-2006-11-14.html 
Centro Cultural El Barro, Campaña por el Aborto Legal, Seguro y Gratuito San Juan, Colectivo Género San Juan, y Mujeres Activistas Independientes (2013). $28^{\circ}$ Encuentro Nacional de Mujeres [Folleto].

Centro Cultural El Barro y Campaña por el Aborto Legal, Seguro y Gratuito San Juan (2014). Una deuda histórica con nuestra soberanía [Folleto].

Chousal Lizama, P. (2021). "Ahora que sínos ven...": Los movimientosfeministas sanjuaninos en la construcción política de lo personal [Ponencia]. IV Jornadas de Sociología 2021: "Agrietar el neoliberalismo en nuestra América", Facultad de Ciencias Políticas y Sociales, Universidad Nacional de Cuyo, Mendoza, Argentina.

Chousal Lizama, P. (2020). Cartografía feminista: Intervenciones por el aborto legal en San Juan-2018 [Ponencia]. VI Congreso Nacional y Provincial de Políticas Públicas, Facultad de Ciencias Sociales, Universidad Nacional de San Juan, Argentina.

Chousal Lizama, P. y Rodríguez Savall, F. (2017). Activismos en disputa. Discursos sobre el aborto. Los casos del Movimiento Apostólico de Schoenstatt y Las Hilarias-Feministas Aborteras, en la provincia de San Juan [Tesis de grado]. Universidad Nacional de San Juan.

Clarín (1997, 5 de junio). Una reunión nacional que se hará en San Juan. Un encuentro de mujeres que despierta polémicas. Clarín. https:// www.clarin.com/sociedad/encuentro-mujeres-despierta-polemicas_0_Sk689ZZRFl.html

Comité Organizador (2011). Segunda Circular. XI Jornadas Nacionales de Historia de las Mujeres y VI Congreso Iberoamericano de Estudios de Género, Universidad Nacional de San Juan, Argentina. http:// www.rimaweb.com.ar/wp-content/uploads/2012/02/SEGUNDA-CIRCULAR_enviar1.pdf

Córdoba, M. D. y Domínguez, M. (2019). Corporalidades y derechos sexuales y (no) reproductivos. Lxs sujetxs del aborto en el debate público sobre la ley de interrupción voluntaria del embarazo [Ponencia]. Pre ALAS San Juan-Argentina, $3 .^{\text {er }}$ Congreso de la Asociación Argentina de Sociología, y 2. as Jornadas Provinciales de Sociología de San Juan, Universidad Nacional de San Juan, Argentina.

Córdoba, M. D., González, S. y Nayar, Y. (2019). Derechos sexuales y (no) reproductivos desde la perspectiva de la diversidad sexual [Ponencia]. Pre ALAS San Juan-Argentina, $3{ }^{\text {er }}$ Congreso de la Asociación Argen- 
tina de Sociología, y 2. as Jornadas Provinciales de Sociología de San Juan, Universidad Nacional de San Juan, Argentina.

Corte Suprema de Justicia de la Nación (2012). F., A. L. S/ Medida autosatisfactiva [Sentencia]. http://www.saij.gob.ar/corte-suprema-justicianacion-federal-ciudad-autonoma-buenos-aires--medida-autosatisfactiva-fa12000021-2012-03-13/123456789-120-0002-1ots-eupmocsollaf

Equipo de Investigación en Género y Ciudadanía (2018, abril). Conversatorio sobre derechos sexuales y (no) reproductivos. El derecho a decidir [Transcripción no publicada]. Instituto de Investigaciones Socio Económicas; Facultad de Ciencias Sociales, Universidad Nacional de San Juan.

Henríquez, G. (2007). Construcción de hegemonía: El proyecto político de Federico Cantoni 1923-1932 (San Juan, Argentina) [Ponencia]. XXVI Congreso de la Asociación Latinoamericana de Sociología, México. https://cdsa.aacademica.org/000-066/928

García, F. (2001). Las mujeres en el orden cantonista. Género, política y cultura en el San Juan de los años 20. En C. López (dir.), Mujeres rescatadas del olvido (pp. 117-150). Facultad de Filosofía, Humanidades y Artes, Universidad Nacional de San Juan.

García, F., Goldberg, M. y Gómez, N. (2009). Lógica social y lógica política. Coexistencia y desfases [Ponencia]. XXVII Congreso de la Asociación Latinoamericana de Sociología, VIII Jornadas de Sociología de la Universidad de Buenos Aires, Buenos Aires, Argentina. https://www. aacademica.org/000-062/1215

Gimeno, D. O. (2018). Poder, sujeto y comunicación. La glorieta LGBT y la marcha del orgullo gay en la provincia de San Juan [Tesis de doctorado]. Universidad Nacional de Córdoba. https://rdu.unc.edu.ar/ handle/11086/13226

Gómez, N. y Goldberg, M. (2013). La reconfiguración del campo político en San Juan. Una aproximación a los gobiernos de Cantoni y Bravo. RevIISE-Revista de Ciencias Sociales y Humanas, 4(4), 57-66. http:// www.ojs.unsj.edu.ar/index.php/reviise/article/view/41

Iglesias Skulj, A. (2020, 9 de marzo). 8M: Un paro para cambiarlo todo. Ministerio de Justicia y Derechos Humanos. https://www.argentina.gob. ar/noticias/8m-un-paro-para-cambiarlo-todo

Instituto Nacional de Estadísticas y Censo (2010). Población total por lugar de nacimiento, según provincia. Censo de 2010: Argentina. https:// www.indec.gob.ar/indec/web/Nivel4-Tema-2-18-77 
Insumisas (2011). Boletín N. ${ }^{0} 1$ [Panfleto].

Iturrieta, Y. (s. f.). Política de aborto en San Juan. Experiencias y desafíos a partir de su legalización (en prensa). Derecho y Ciencias Sociales. Universidad Nacional de La Plata.

Iturrieta, Y. (2021a). La política feminista del cuidado de Socorristas en Red. Experiencia organizativa y sistematización de acompañamientos de Las Hilarias en San Juan. Revista Tramas Sociales, 3(3), 101-133. http:// www.ojs.unsj.edu.ar/index.php/tramassociales/article/view/618

Iturrieta, Y. (2021b). Estrategias de organizaciones feministas para la ampliación del acceso a ILEs en San Juan, en el marco de la pandemia por COVID-19 [Ponencia]. XIV Jornadas de la Carrera de Sociología, Facultad de Ciencias Sociales, Universidad de Buenos Aires, Argentina.

Iturrieta, Y. (2019). La experiencia de mujeres que abortan en San Juan acompañadas por Socorristas en Red. Periodo 2016-2018 [Tesis de grado]. Universidad Nacional de San Juan.

Iturrieta, Y. (2018). Mapeo del escenario nacional después del debate por la legalización del aborto. Aportes desde la provincia de San Juan [Manuscrito no publicado]. Departamento de Sociología, Facultad de Ciencias Sociales, Universidad Nacional de San Juan.

Iturrieta, Y. y Sillero E., G. (2021). Participación social y ciudadanía política de mujeres sanjuaninas ante las reformas cantonistas de comienzos del Siglo XX [Ponencia]. XI Jornadas de Historia Moderna y Contemporánea, Universidad Nacional Del Sur, Argentina.

Jelin, E. (2020). Las tramas del tiempo: Familia, género, memorias, derechos y movimientos sociales. Antología esencial. Consejo Latinoamericano de Ciencias Sociales. http://biblioteca.clacso.edu.ar/clacso/ se/20201222032537/Antologia-Elizabeth-Jelin.pdf

Las Hilarias Socorristas en Red (2020, 14 de agosto). En un Mundo Justo, las Niñas No son Madres. Radio La Lechuza. http://www.radiolalechuza. com.ar/en-un-mundo-justo-las-ninas-no-son-madres /

Las Hilarias Socorristas en Red San Juan, Red de profesionales de la salud por el derecho a decidir San Juan, Espacio de Sociología Feminista(s), Departamento de Sociología, Ni unx Menos San Juan, Red de Comunicadorxs con Perspectiva de Género y Equipo de Investigación Género y Sexualidades (2019, junio). Jornadas de incidencia sobre derechos sexuales, reproductivos y no reproductivos en San Juan. Abor- 
dajes de instituciones y movimientos sociales en el ámbito de la salud, la educación, la comunicación y el derecho [Convocatoria] [Nota]. Facebook. https://www.facebook.com/notes/1079545285795565/ Ministerio de Salud de la Nación (2010). Guía Técnica para la Atención Integral de los Abortos No Punibles. https://argentina.unfpa.org/ es/publicaciones/gu\%C3\%AD-t\%C3\%A9cnica-para-la-atenci\%C3\%B3n-integral-de-los-abortos-no-punibles

Naveda, A. B. (2021). Alternativas al extractivismo minero: Otras producciones son posibles. Editorial Universidad Nacional de San Juan.

Ni Unx Menos San Juan (2021, 4 de marzo). Respecto al cambio de nuestro logo [Publicación]. Facebook. https://www.facebook.com/NiUnaMenosSanJuan/photos/a.727286537416459/2386536421491454

Ni Unx Menos San Juan (2017, 8 de marzo). La tierra tiembla. Se siente... ¡Paro Mundial de Mujeres! [Declaración] [Publicación]. Facebook. https://www.facebook.com/NiUnaMenosSanJuan/photos/ a.727286537416459/1014088332069610/

Página 12 (2017, 9 de marzo). El documento completo del 8-M. ¿Por qué paramos? https://www.pagina12.com.ar/24628-por-que-paramos

Pessio, F. (2020, 3 de julio). Conversaciones Feministas: Las Hilarias. El Cimbronazo. https://elcimbronazo.com/2020/07/03/conversaciones-feministaslas-hilarias/

Ramella, S. (1985). El radicalismo bloquista en San Juan, 1916-1934. Gobierno de San Juan, Consejo Nacional de Investigaciones Científicas y Técnicas.

Red de Comunicadorxs con Perspectiva de Género de San Juan (2018). Información [Página de Facebook]. RECOPE San Juan. https://www. facebook.com/recope.sanjuan/about

Rodríguez Ruarte, M. (2019, septiembre). Las mujeres militantes de la Asamblea "Jáchal No se toca". Entre la maternidad y la estigmatización [Ponencia]. Pre ALAS San Juan-Argentina, 3. ${ }^{\text {er }}$ Congreso de la Asocia-

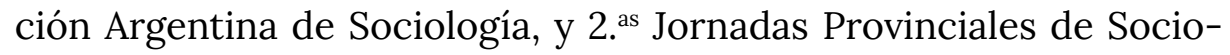
logía de San Juan, Universidad Nacional de San Juan, Argentina.

Salcedo, E. (2018, 27 de abril). Las primeras mujeres elegidas por voto universal. Revista de la U. http://www.revista.unsj.edu.ar/?p=2911

Socorristas en Red (feministas que abortamos) (2021). En un Mundo Justo, las Niñas No son Madres. https://socorristasenred.org/en-un-mundo-justo-las-ninas-no-son-madres-2021/ 
Toledo, R. (2021, 10 de julio). La historia de los Encuentros Nacionales de Mujeres: Séptima parte. Nota al Pie. https://www.notaalpie.com. ar/2021/07/10/la-historia-de-los-encuentros-nacionales-de-mujeres-septima-parte/

Valobra, A. M. (2008). La ciudadanía política de las mujeres y las elecciones de 1951. Anuario del Instituto de Historia Argentina, (8), 53-89. http:// sedici.unlp.edu.ar/handle/10915/12369

Zurbriggen, R. y Anzorena, C. (comps.) (2013). El aborto como derecho de las mujeres. Otra historia es posible. Herramienta. 